\title{
Space-time Gaussian models for evaluating corrosion-induced damages in reinforcing bars
}

\author{
S MUTHULINGAM ${ }^{1,2}$ \\ ${ }^{1}$ Department of Civil Engineering, Sri Sivasubramaniya Nadar (SSN) College of Engineering, \\ Kalavakkam 603 110, India \\ ${ }^{2}$ Centre of Infrastructure Performance and Reliability, The University of Newcastle, Callaghan, \\ New South Wales 2308, Australia \\ e-mail: gs.muthulingam@gmail.com
}

MS received 4 July 2016; accepted 28 October 2018; published online 2 January 2019

\begin{abstract}
Chloride-induced steel reinforcing bars corrosion is a problem of worldwide importance because, in addition to massive industrialization, a majority of human population inhabit marine atmosphere zones where salinity is the main source of built infrastructure deterioration. Reinforced concrete structures vulnerable to chloride-induced corrosion potentially experience two stages of damage, namely non-structural and structural. Till date, with regard to non-uniform corrosion, there is very limited information regarding the significant role played by the non-structural stage of damage in influencing the progression of structural damage. The present work examines the process of non-uniform chloride ingress into concrete due to the existence of the steel bars and its influence on the spatial and temporal variations in the depth of corrosion penetration. Mathematical models in the form of Gaussian functions are proposed to represent space-time variation in corrosion initiation, spatial spread of corrosion penetration depth and corroded bar morphologies, and are compared with literature data. A numerical inverse analysis procedure is introduced to predict space-time evolution of non-structural damage from experimentally observed spatial spread of structural damage. Further, applicability of superposition approach for the evaluation of corrosion-induced stresses around the steel-concrete interface of a corner reinforcing bar is explored and shown to introduce spatial and temporal errors while evaluating structural damages.
\end{abstract}

Keywords. Concrete structures; chlorides; corrosion; damage; modelling.

\section{Introduction}

The presence of steel bars in reinforced concrete (RC), to a great degree, enhances the structural performance in terms of strength and serviceability limit states. However, the same steel bars have the potential to severely compromise the limit states and thus could lead to premature deterioration and service interruption of infrastructure facilities when subjected to corrosion under aggressive environments [1]. This is a cause for worldwide concern because, in addition to massive industrialization, a majority of human population inhabit marine atmosphere zones where salinity is the main source of built infrastructure deterioration. The most likely cause being chloride-induced corrosion of steel bars embedded in concrete.

The RC structures vulnerable to chloride-induced corrosion potentially experience two stages of damage, namely non-structural and structural. During the former, the chloride ions, slowly and progressively, penetrate through the porous concrete cover and disrupt the passive protective film present around the steel bar thus initiating corrosion. After corrosion initiation, the RC structures, within a short period of time, exhibit severe structural damages such as reduction in cross-sectional area of the steel bar, concrete cover cracking, delamination, and spalling [2]. The nonstructural and structural stages of damage can be viewed as analogous to the corrosion initiation and corrosion propagation phases of a typical service life model for RC structures under chloride environments (e.g., [3]). While vulnerable $\mathrm{RC}$ elements in an infrastructural system undergo frequent intervention in the form of visual inspections, the non-structural damage is hardly spotted in most cases unless advanced detection methods are used. This is because a routine visual inspection can identify only the perceptible damages such as corrosion-induced cracks, rust stains on the surface of the concrete, which occur during the structural stage [4]. To overcome this particular limitation, knowledge available in the literature suggests analytical and mathematical models as potential alternatives. The traditional error function based solutions to Fick's second law of diffusion, though, analytical simple, 
are rarely valid, specifically, for RC structures under natural chloride environments [5]. Hence, well-established physics-based mathematical models that incorporate details about transport mechanisms, binding nature of the concrete matrix, and effects of external environmental conditions are preferred (e.g., [6, 7]).

The act of disruption of the passive protection film around the steel bar marks the end of the non-structural stage of damage and beginning of the structural stage. It is commonly agreed that a chloride threshold value at the steel bar level causes its depassivation (e.g., [8]), though other factors such as imperfections at the steel-concrete interface, electrochemical potential of the steel, and electrical resistivity of the concrete also play a role [1,9]. It may be noted here that due to the impermeable nature of the steel bars, the chloride ions would display variations, both spatially and temporally, along the circumference of the metal surfaces. That is, the content of chloride ions would be higher on the surface of the bar facing the external chloride environment and progressively decrease as they evolve towards the metal surface facing the interior of concrete. Therefore, in the presence of steel bars, the process of chloride ingress into concrete would be non-uniform in nature and thus the consideration that a chloride threshold value initiates active corrosion of the bar would lead to spatial and temporal variations in corrosion initiation along the circumference of the bar [10-12]. This being the real situation, numerous studies (e.g., $[13,14])$ assume uniform corrosion initiation, which implies simultaneous depassivation along the entire metal surface at a single point in time. The assumption of uniform corrosion initiation may be acceptable in the case of a concrete mix having initial chlorides high enough to cause depassivation over time (e.g., [15]); however, unrealistic in concrete under natural exposure conditions.

The chloride-induced corrosion damages are influenced by various factors. For instance, factors such as concrete quality, aging of concrete, ambient temperature and moisture in the external environment play a significant role during the non-structural stage [16]. Moreover, the duration of the non-structural stage of damage is governed by a single parameter, namely time-to-corrosion initiation, $T_{i}$ (years). It is defined as the time by chloride ions, from external environments, to penetrate the concrete cover and reach the critical chloride value at the steel bar level. Further, the measure of damages in the structural stage expressed either as the time to attainment of a pre-defined limit state or its severity at a given time, is highly sensitive to the rate of corrosion [17, 18]. In recent years, more attention has been paid towards investigating the structural stage of damage $[13,19,20]$. This allows for the efficient integration of realistic strength and serviceability limit states into a failure model such as crack widths exceeding a permissible value, actual load effects surpassing the resistance at any structural element, and severe cover cracking [1]. However, in most cases, the models assume uniform depth of corrosion penetration along the circumference of the steel bar $[2,13,19,20]$. Contrary to this assumption, recent investigations on microstructure and the spatial distribution of corrosion products, as well as inspections of steel bars removed from corroded concrete exposed to chloride environments, reveal non-uniform corrosion pattern as the actual situation [21-23]. Note that in this work non-uniform corrosion pattern is distinguished from pitting by corrosion scenarios where only a part of the steel bar circumference is corroding and where corrosion is taking place unevenly along the circumference of the steel bar $[11,22]$.

Till date, with regard to non-uniform corrosion, there is very limited information regarding the significant role played by the non-structural stage of damage in influencing the progression of structural damage. For instance, early events during the structural stage of damage mainly involve the transformation of steel into corrosion products - an expansive process, which initiates cover cracking of concrete thereby providing a possible pathway for the faster and higher penetration of chloride ions thus accelerating the depassivation process in the protected areas of the reinforcing bar [21]. Even though such distribution of corrosion products layer has been shown to be spatially varying around the steel bar surface [21], the cause and its connection with the non-structural stage of damage remain to be identified. Such explorations are critical since they provide a coherent description of the corrosion process under natural exposure. The present work focuses on this point by examining the process of non-uniform chloride ingress into concrete due to the existence of the steel bars and its influence on the spatial and temporal variations in the depth of corrosion penetration. Mathematical models in the form of Gaussian functions are proposed at every stage of the corrosion process and compared with laboratory and field data available in the literature.

\section{Corrosion process modelling}

The process of non-uniform chloride ingress into RC during the non-structural stage of damage is a complex physiochemical phenomenon $[6,24]$. This process is not only characterized by the occurrence of distinctly different, yet simultaneous, modes of chloride ingress mechanisms such as diffusion and convection but also involves a coupling of different physical processes with various material characteristics of the concrete matrix. Under natural exposure condition, one of the effective ways to model the chloride ingress process is to consider it as an interaction between three physical phenomena, namely heat transfer, moisture diffusion, and chloride ingress [6, 7]. This approach belongs to single ionic type for it considers only the penetration of chloride ions as opposed to multi-ionic models that incorporate interactions between various ions present 
in the concrete matrix [5]. In this work, a single-ionic model presented in [6, 7] is adopted as it is relatively simple to implement, associated material characteristics are easily obtainable, and it incorporates non-linear chloride binding and the effects of external environmental conditions on the process of chloride penetration. Each of these physical phenomena is represented by means of a field equation, and their interaction is considered by solving them simultaneously using a numerical approach - a combination of finite element (FE) and finite difference scheme. These field equations along with the numerical method are detailed in $[10,11]$.

Note that all the coefficients and factors, concerning the chloride ingress model, adopted in the current work are the same as described in $[10,11]$ except the reference chloride diffusion coefficient, $D_{c, \operatorname{Ref}}\left(\mathrm{m}^{2} / \mathrm{s}\right)$, the chloride binding isotherms constant, and the factor that modifies relative humidity, $f_{h}(h)$. In this study, $D_{c, \text { Ref }}$ is evaluated by the following equation [25]:

$$
D_{c, \text { Ref }}=10^{\left(0.4821(w / b)^{2}+0.2127(w / b)-0.0136 f-0.2824\right)}
$$

where $w / b$ represents water-to-binder ratio (a ratio by mass) and $f$ indicates the percentage of fly ash replacement in concrete, which is considered to be zero in this study. Further, for the purpose of evaluating the relationship between bound and free chlorides two types of binding isotherms are commonly used, namely Langmuir isotherm and Freundlich isotherm [26], which involve different constants called as binding isotherm constants viz, $\kappa_{\alpha_{L}}(\mathrm{~mL}$ pore solution/g sample), $\kappa_{\beta_{L}}(\mathrm{~mL}$ pore solution/mg $\mathrm{Cl}), \kappa_{\alpha_{F}}$ (mL pore solution/g sample), and $\kappa_{\beta_{F}}$ represent chloride binding isotherm constants. These constants are detailed in $[7,10]$. In the current study, binding isotherm constants are evaluated as follows [25]:

$$
\kappa_{\alpha_{L}, \alpha_{F} \cdot \beta_{L} \cdot \beta_{F}}=\eta_{1}+\eta_{2} f
$$

where $\eta_{1}$ and $\eta_{2}$ are fitting coefficients unique to each binding isotherm constant. In this work the values of $\kappa_{\alpha_{L}}$, $\kappa_{\beta_{L}}, \kappa_{\alpha_{F}}$, and $\kappa_{\beta_{F}}$ are taken as $0.4621,0.0799,1.2354$, and 0.3237 , respectively [25]. Further, based on the theory of non-linear moisture diffusion, $f_{h}(h)$ is given as [27]:

$$
f_{h}(h)=\lambda_{h}+\mu_{h}\left[1-2^{-10^{v_{h}(h-1)}}\right]
$$

where $\lambda_{h}, \mu_{h}$, and $v_{h}$ are coefficients to be evaluated from experimental data. In Eq. (3), $\lambda_{h}$ denotes the lower bound of $f_{h}(h)$ at low humidity level, $\mu_{h} / 2$ represents the difference in $f_{h}(h)$ between low humidity level and saturation state, and $v_{h}$ corresponds to the level of humidity at which $f_{h}(h)$ begins to increase [27].

During the structural stage of damage, the depth of corrosion penetration, $p_{d}$ (in $\mathrm{mm}$ ), represents the timevariant corrosion loss of the steel bars. Note that, based on Faraday's law, $p_{d}$ can be estimated as follows [28]:

$$
p_{d}(t)=\int_{T_{i}}^{t} 0.0116 i_{\text {corr }}(r) \mathrm{d} t
$$

where $t$ indicates exposure period in years and $i_{\text {corr }}(t)$ represents time-variant nature of the corrosion rate in $\mu \mathrm{A} / \mathrm{cm}^{2}$. Note that Eq. (4) is valid for $t>T_{i}$. An accurate and realistic model of $i_{\text {corr }}$ is critical for evaluating the extent of structural damage, or in other words, for estimating the service life of RC structures during the structural stage of damage. Since, $i_{\text {corr }}$ under natural exposure condition is influenced by various factors such as cover depth, chloride content, water-to-binder ratio, levels of humidity and temperature, etc., various prediction models have been proposed in the literature taking into account one or more of these factors. A review of the merits and limitations of various $i_{\text {corr }}$ prediction models can be found in [17]. In this work, $i_{\text {corr }}(t)$ is evaluated by the following equation [29]:

$$
i_{\mathrm{corr}}(t)=\frac{32.13[1-(w / b)]^{-1.64}}{C_{d}}\left(t-T_{i}\right)^{-0.29}
$$

where $w / b$ represents water-to-binder ratio and $C_{d}$ indicates cover depth (in $\mathrm{cm}$ ), which measures the distance between the exterior face of the concrete to the surface of the reinforcing bar. By substituting Eq. (5) into Eq. (4), $p_{d}$ can be evaluated as a function of time.

The models used to investigate the non-structural and structural stages of damage are cast into an FE framework, which sequentially solves the space-time evolution of the physical variables such as temperature, humidity, and chloride at incremental time steps along with the corrosion loss estimates of steel bars. The important aspects of the FE procedure include discretizing of the chosen computational domain with appropriate FE and enforcement of pertinent boundary conditions explicit to the type of physical problem under consideration. In the current work, a cross-section of an $\mathrm{RC}$ beam section of size $350 \mathrm{~mm} \times 700 \mathrm{~mm}$ is chosen as the domain (see figure 1(a)). This RC beam embeds four reinforcing bars on its tension face and they, based on their positions, can be classified either as a corner bar, $\mathrm{R}_{\mathrm{c}}$ or a middle bar, $\mathrm{R}_{\mathrm{m}}$. Further in figure $1(\mathrm{a}), C_{d}$ is the cover depth (in $\mathrm{mm}$ ) and $d_{r}$ represents the diameter of the reinforcing bar. Moreover, the RC beam as well as the reinforcing bars are discretized with a four-noded quadrilateral element having an edge size of approximately $5 \mathrm{~mm}$ (see figure 1(b)). Note that the edges of the reinforcing bars are discretised with forty numbers of FE nodes so as to smoothly capture the evolution of physical variables in the computational domain.

To simulate the natural exposure condition, the $\mathrm{RC}$ is assumed to be constructed near the shoreline of Tohoku region in Japan. This area is selected for the presence of high content of sea salts in the atmosphere, which poses a great danger to the built infrastructural facilities in terms of premature deterioration, service interruption, and safety failure. Further, the boundary conditions in the form of local chloride content, relative humidity, and temperature needs to be 
(a)

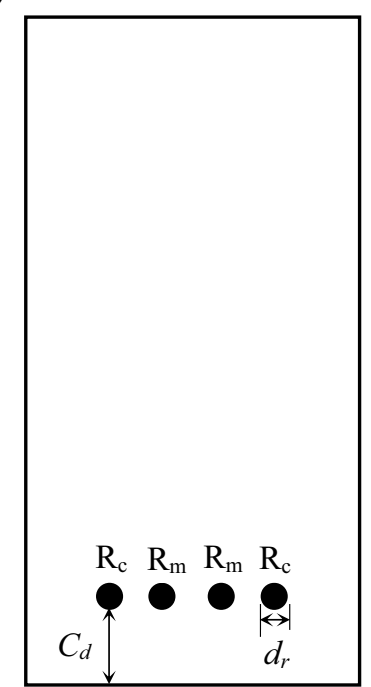

(b)

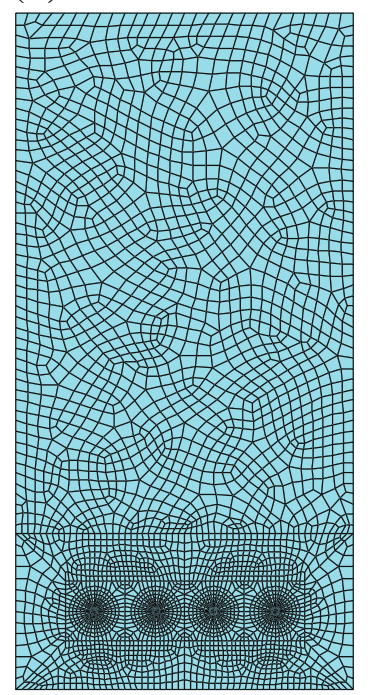

Figure 1. Geometry of the RC element and finite element discretization.

prescribed as boundary conditions to the FE model. In this regard, a constant surface chloride content of $9 \mathrm{~kg} / \mathrm{m}^{3}$ is enforced at the exposed surfaces of the RC beam, temperature and relative humidity data specific to Tohoku region are obtained from Japan Meteorological Agency [30]. From the data, it was observed that both relative humidity and temperature follow harmonic trends and that mathematical functions in the form of sine curves can be fitted as follows:

$$
\begin{gathered}
T_{\text {env }}(t)=286.05+11.3 \sin (2 \pi t) \\
H_{\text {env }}(t)=0.725+0.105 \sin [2 \pi(t-0.5)]
\end{gathered}
$$

where $t$ is in years $(0 \leq t \leq 1.0)$. Furthermore, during numerical simulation cover depths $(25-75 \mathrm{~mm})$ and reinforcing bar sizes $(12,16,20$, and $25 \mathrm{~mm})$ are considered as variables. Note that a water-to-binder ratio $(=0.5)$ is considered for numerical analyses. The simulation variables corresponding to a particular result sequence, presented in the following sections, are identified as $\mathrm{R}_{\mathrm{c}} / \mathrm{R}_{\mathrm{m}}-d_{r}-C_{d}$. For instance, the simulation variable $\mathrm{R}_{\mathrm{m}}-20-50$ corresponds to the numerical analysis pertaining to a middle reinforcing bar $\mathrm{R}_{\mathrm{m}}$, bar size $d_{r}=20 \mathrm{~mm}$, and cover depth $C_{d}=50 \mathrm{~mm}$. Finally, simulations are conducted over a period of hundred years adopting the numerical procedure detailed in [11], and the evolution of temperature, humidity, chloride content and depth of corrosion penetration are traced at every incremental time step equal to one day.

\section{Non-structural stage of damage}

The process of non-uniform chloride ingress into $\mathrm{RC}$ in the presence of reinforcing bars leads to space-time variations in non-structural damage along the circumference of the bar. As indicated earlier, the extent of non-structural damage is governed by the single parameter, $T_{i}$. Figure 2(a) illustrates the effects of $C_{d}$ on space-time propagation of non-structural damage along the circumferences of $R_{m}$ and $R_{c}$. For illustration purposes, the values of $C_{d}$ are taken as $25,35,45$, and 55 $\mathrm{mm}$ while $d_{r}$ is kept constant equal to $12 \mathrm{~mm}$. As shown in figure 2(a), on the time scale of 100 years, an increase in $C_{d}$ delays space-time propagation of $T_{i}$ in both $\mathrm{R}_{\mathrm{m}}$ and $\mathrm{R}_{\mathrm{c} \text {. This is }}$ because an increase in cover depth increases the distance between the face of $\mathrm{RC}$ beam and the reinforcing bar thereby increasing the time required for chlorides to reach the threshold value at the bar level. Further, figure 2(b) shows that a rise in $d_{r}$ size also affects $T_{i}$, specifically for $\mathrm{R}_{\mathrm{m}}$. An increase in size, especially for $R_{m}$, magnifies the area of obstruction for the chloride ions to pass through; hence, chlorides keep mounting over time in front of the bar leading to quicker corrosion initiation. However, this behavior appears to be limited to a particular perimeter length of $R_{m}$ facing the external environment. After this specific edge length, the trends seem to shift from faster $T_{i}$ with increasing $d_{r}$ to slower $T_{i}$ with increasing $d_{r}$. Such changes in trends convey although the increase in $d_{r}$ would assist early setting in of the corrosion reaction in the bar would relatively delay corrosion initiation in the areas of steel facing the interiors of concrete.

The space-time propagations of non-structural damage shown in figures 2(a) and (b) can be categorized into two schemes (see figure 3): scheme-I and scheme-II. Scheme-I corresponds to situations where the propagation of nonstructural damage is complete while scheme-II refers to the incomplete or partial spread of non-structural damage along the steel bar circumference. Note that in terms of corrosion loss during the structural stage of damage, scheme-I situations could be interpreted to be comparatively more severe than that due to scheme-II circumstances. In figure $3, T_{i}^{1}$ refers to the time when the corrosion reaction set in first while $T_{i}^{\max }$ indicates the maximum value of time-to-corrosion initiation over the simulation period of 100 years. By comparing figures 2(a) and (b) with figure 3 , it can be observed that $T_{i}^{1}$ is shorter for $\mathrm{R}_{\mathrm{c}}$ when compared with that for $\mathrm{R}_{\mathrm{m}}$ and the location of $T_{i}^{1}$ is slightly shifted in the case of $R_{c}$. In addition, figure 3 shows that the incomplete ends of scheme-II profiles subtend angles $\theta_{\min }$ and $\theta_{\max }$ (in degrees) with the center of the steel bar.

The space-time propagation of non-structural damage data in figures 2(a) and (b) were fitted with several forms of mathematical equations such as Gaussian, elliptical, and semi-elliptical, and it was found that an equation based on a Gaussian function is more appropriate to describe $T_{i}$ evolutions along steel bar perimeters under both scheme-I and scheme-II cases:

$$
T_{i}=\frac{v_{1}}{v_{2} \sqrt{2 \pi}} e^{-\frac{(\theta-180)^{2}}{2 v_{2}^{2}}}+T_{i}^{1}
$$

where $v_{1}$ and $v_{2}$ represent regression parameters. In Eq. (8), first part describes the non-uniform component of a $T_{i}$ 

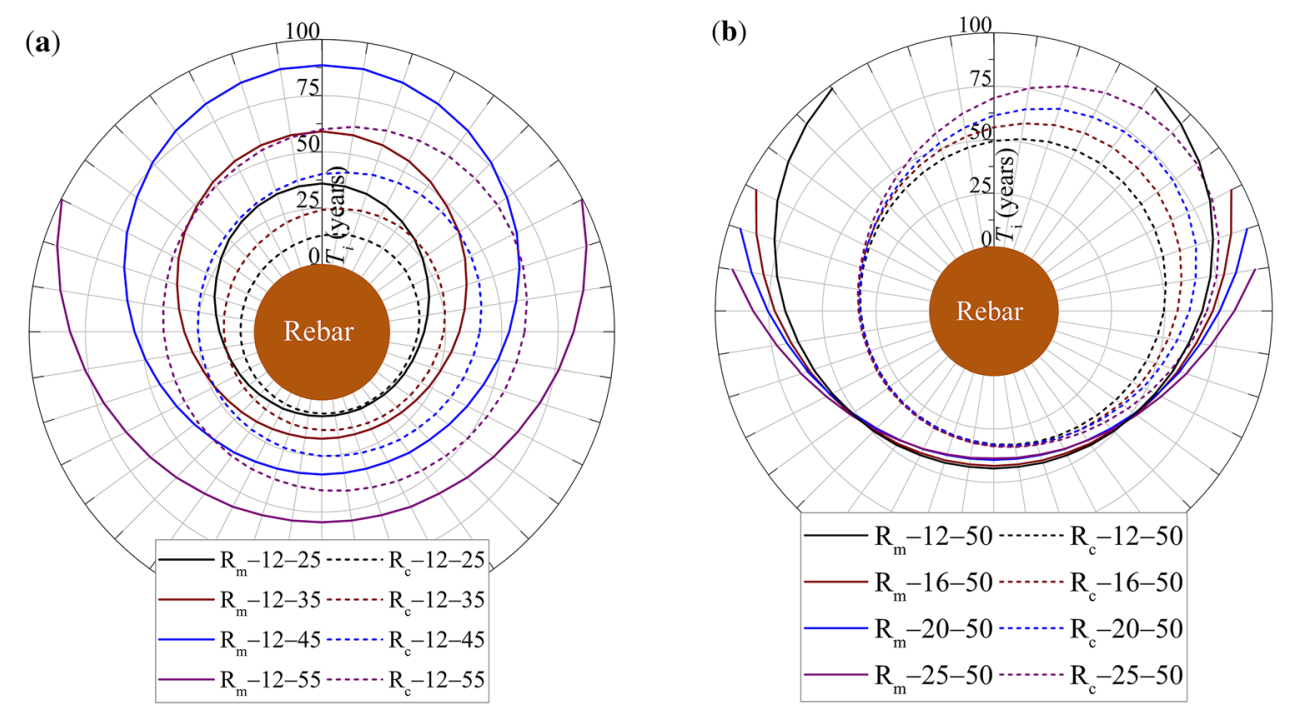

Figure 2. Space-time propagation of non-structural damage: (a) Influence of $C_{d}$; (b) Influence of $d_{r}$.

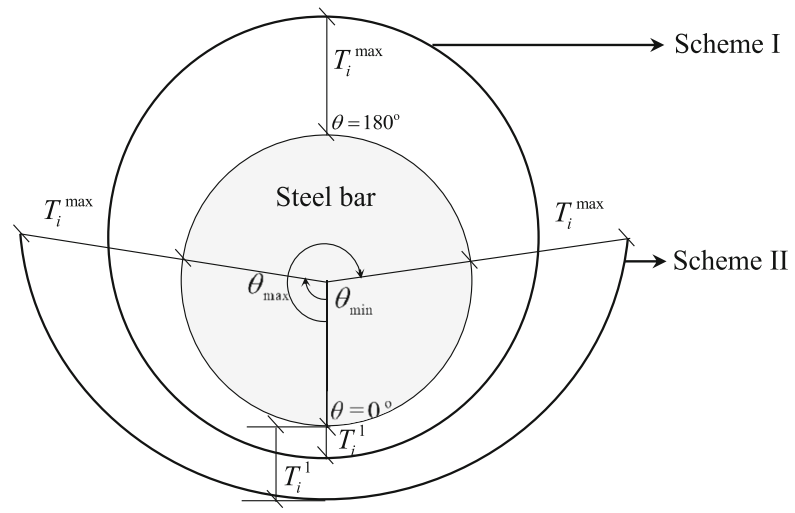

Figure 3. Classification of non-structural damage schemes.

profile while the second part refers to the uniform component of a $T_{i}$ profile. Hence, the proposed Gaussian model could be interpreted as a superposition of uniform and nonuniform components of an $T_{i}$ evolution. Further, the regression parameters $v_{1}$ and $v_{2}$ signify various features of the fitted profile. For instance, $v_{1}$ and $v_{2}$ correlate to the maximum value and the spread of $T_{i}$ along the steel bar perimeter. Note that $T_{i}^{1}$ relates to the value of time-tocorrosion initiation under the widely adopted assumption of uniform corrosion (e.g. [2]); however, the significant difference, in this current work, is that $T_{i}^{1}$ is evaluated taking into account the major role played by the steel bars during the process of chloride ingress.

To illustrate that the Gaussian model can best represent the space-time propagation of non-structural damage, $T_{i}$ profiles data, both scheme-I and scheme-II, shown in figures 2(a) and (b) each representing either the effects of $C_{d}$ on $T_{i}$ or $d_{r}$ on $T_{i}$ are chosen. Figures 4(a) and (b) show the distribution of selected $T_{i}$ profiles data superposed with trend lines drawn through the data points using the proposed model. It can be seen that the regression analysis provided best-fits for all types of $T_{i}$ profiles with estimated R-Square values higher than 0.99 , which show the presence of a very strong linear relationship between the simulation and regression data. Hence, it is clear that the proposed Gaussian model can best represent variation in both scheme-I and scheme-II profiles of $T_{i}$. Further, table 1 lists the values of regression parameters $v_{1}$ and $v_{2}$ along with their corresponding $T_{i}^{1}$, R-Square, $\theta_{\min }$, and $\theta_{\max }$ values for the simulation variables conforming to figures 4 (a) and (b). Note that an unknown variable $\mathrm{X}$ is used in the first column of table 1 to relate the simulation variable with either $R_{c}$ or $\mathrm{R}_{\mathrm{m}}$.

It can be observed from table 1 that, irrespective of the type of schemes, increase in $C_{d}$ increases $v_{1}$ for both $\mathrm{R}_{\mathrm{c}}$ and $\mathrm{R}_{\mathrm{m}}$ indicating a decrease in the levels of chloride ions diffusivity. Further, $v_{2}$ increases with increase in $C_{d}$ for $\mathrm{R}_{\mathrm{c}}$ and $R_{m}$ for scheme-I cases. As can be noticed from figures 2(a) and (b), a rise in $v_{2}$ with a gain in $C_{d}$ shows a relatively flatter profile of $T_{i}$ having less non-uniform component. This behaviour can also be verified from table 1 , where the ratios of $T_{i}^{\max } / T_{i}^{1}$ can be found to decrease with increasing values of $C_{d}$. It appears that, in general, an increase in $C_{d}$ values result in space-time propagations of non-structural damage, even though nonuniform, would be relatively flatter in nature. On the contrary, a rise in $d_{r}$ is observed to decrease $v_{2}$ for both $\mathrm{R}_{\mathrm{c}}$ and $\mathrm{R}_{\mathrm{m}}$ reflecting a steady increase in the steeper shape of the $T_{i}$ profile (see figures 2(a) and (b)). This behaviour implies that the non-uniform component of a $T_{i}$ profile would be more dominantly present under these circumstances. The following may serve as a further explanation about the 
(a)

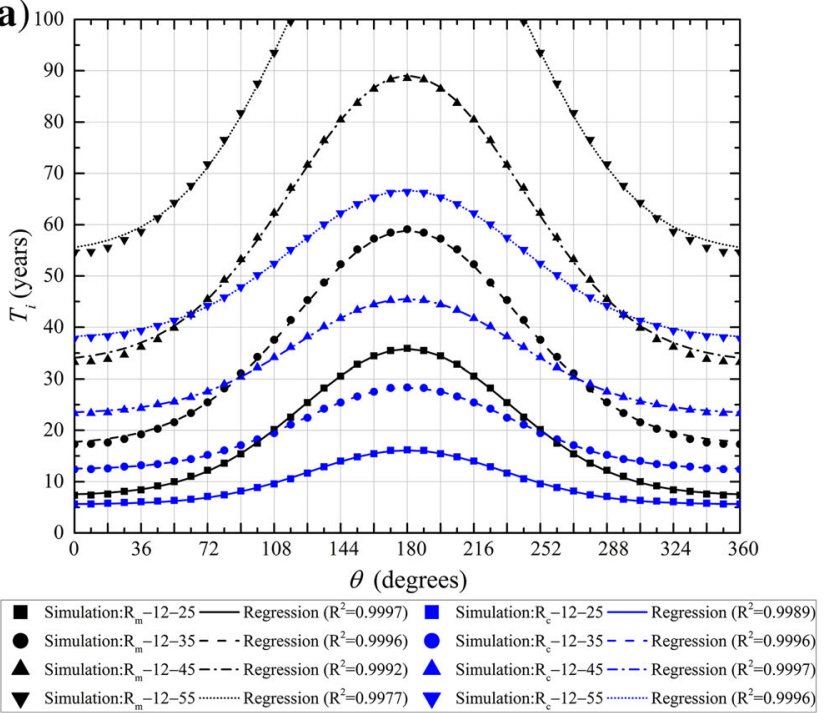

(b)

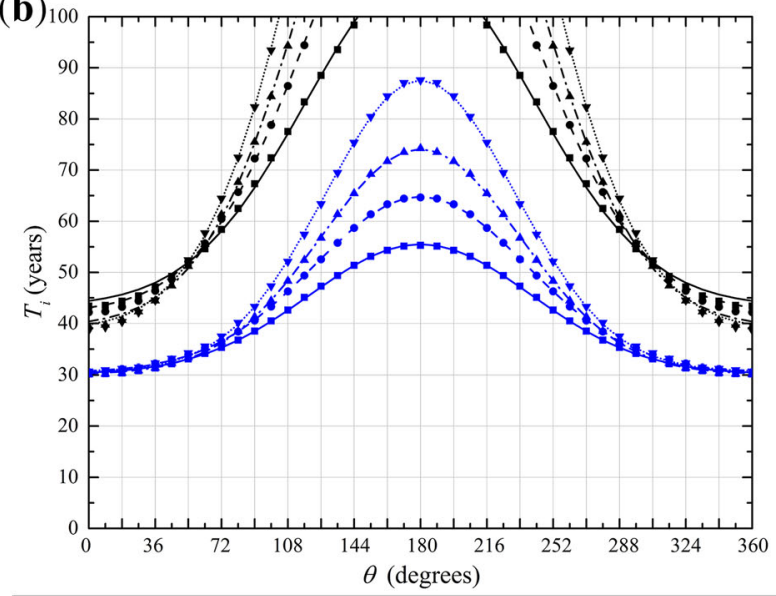

Simulation: $R_{m}-12-50-$ Regression $\left(R^{2}=0.9988\right)$ Simulation: $R_{0}-12-50-R e g r e s s i o n\left(R^{2}=0.9996\right)$ Simulation: $R-16-50$ - - - Regression $\left(R^{2}=0.9987\right)-$ Simulation: $R-16-50--$ - Regression $\left(R^{2}=0.9998\right)$ Simulation: $R_{m}-20-50-\cdot \cdot \cdot$ Regression $\left(R^{2}=0.9989\right) \Delta$ Simulation: $R-20-50-\cdot-\cdot$ Regression $\left(R^{2}=0.9999\right)$ Simulation: $\mathrm{R}_{\mathrm{m}}-25-50 \cdots \cdots \cdots \cdots \cdot$ Regression $\left(\mathrm{R}^{2}=0.9990\right) \quad \boldsymbol{\nabla}$ Simulation: $\mathrm{R}_{\mathrm{c}}-25-50 \cdots \cdots \cdots$. Regression $\left(\mathrm{R}^{2}=0.9981\right)$

Figure 4. Regression analysis of the proposed Gaussian model on the data points of $T_{i}$.

Table 1. Values of $v_{1}$ and $v_{2}$ obtained from regression analysis of $T_{i}$ profiles.

\begin{tabular}{|c|c|c|c|c|c|c|c|c|c|c|c|c|}
\hline \multirow[b]{2}{*}{ Variable } & \multicolumn{2}{|c|}{$\begin{array}{c}T_{i}^{1} \\
\text { (years) }\end{array}$} & \multicolumn{2}{|c|}{$v_{1}$} & \multicolumn{2}{|c|}{$v_{2}$} & \multicolumn{2}{|c|}{$\mathrm{R}^{2}$} & \multicolumn{2}{|c|}{$\begin{array}{l}\theta_{\min }, \theta_{\max } \\
\text { (degrees) }\end{array}$} & \multicolumn{2}{|c|}{$T_{i}^{\max } / T_{i}^{1}$} \\
\hline & $X=R_{c}$ & $\mathrm{X}=\mathrm{R}_{\mathrm{m}}$ & $X=R_{c}$ & $\mathrm{X}=\mathrm{R}_{\mathrm{m}}$ & $X=R_{c}$ & $\mathrm{X}=\mathrm{R}_{\mathrm{m}}$ & $X=R_{c}$ & $\mathrm{X}=\mathrm{R}_{\mathrm{m}}$ & $X=R_{c}$ & $\mathrm{X}=\mathrm{R}_{\mathrm{m}}$ & $X=R_{c}$ & $\mathrm{X}=\mathrm{R}_{\mathrm{m}}$ \\
\hline$X-12-25$ & 5.6 & 7.3 & 1387.74 & 4053.65 & 52.78 & 56.83 & 0.9990 & 0.9998 & - & - & 2.9 & 4.9 \\
\hline$X-12-35$ & 12.4 & 17.3 & 2285.31 & 6217.32 & 57.37 & 59.71 & 0.9996 & 0.9996 & - & - & 2.3 & 3.4 \\
\hline$X-12-45$ & 23.3 & 33.2 & 3318.32 & 8683.87 & 59.55 & 61.98 & 0.9997 & 0.9993 & - & - & 1.9 & 2.7 \\
\hline$X-12-55$ & 37.8 & 54.5 & 4465.81 & 11969.65 & 61.68 & 61.61 & 0.9996 & 0.9978 & - & 117,243 & 1.8 & 1.8 \\
\hline$X-12-50$ & 30.2 & 43.4 & 3819.82 & 10269.65 & 60.23 & 62.35 & 0.9996 & 0.9988 & - & 126,234 & 1.8 & 2.3 \\
\hline$X-16-50$ & 30.6 & 42.2 & 4953.87 & 13800.39 & 57.70 & 59.27 & 0.9999 & 0.9987 & - & 117,243 & 2.1 & 2.2 \\
\hline$X-20-50$ & 30.1 & 39.4 & 5982.48 & 17337.68 & 54.24 & 58.12 & 0.9999 & 0.9989 & - & 108,252 & 2.5 & 2.4 \\
\hline$X-25-50$ & 30.7 & 38.7 & 7390.81 & 21578.86 & 51.80 & 57.14 & 0.9998 & 0.9990 & - & 99,261 & 2.9 & 2.4 \\
\hline
\end{tabular}

implications of a steeper $T_{i}$ profile. A steeper $T_{i}$ profile signifies a presence of $T_{i}^{\max }$ much higher than $T_{i}^{1}$ indicating such a profile has greater non-uniform component. The practical significance of these findings is that that the effect of non-uniform corrosion induced structural damages could potentially increase with a rise in the sizes of either or both of $R_{m}$ and $R_{c}$. In this regard, an experimental study [31] reveals that, for a given value of $C_{d}$, the failure pressure required to cause cover-cracking of concrete reduces with increase in $d_{r}$, which is attributed to a greater expansive force generated by the larger-sized bar.

Yet another important observation based on the position of reinforcing bars is that chloride ingress is two-dimensional in the case of $R_{c}$ whereas it is one-dimensional in the case of $R_{m}$. This is one of the primary reasons for faster corrosion initiation and a larger spread of non-structural damage along the circumference for $R_{c}$ when compared with that for $\mathrm{R}_{\mathrm{m}}$. More information about the effect of reinforcing bar position on $T_{i}$ can be found in [11], where it is stated that the value of $T_{i}^{1}$ could be up to $60 \%$ lower in the case of $R_{c}$ when compared with that of $R_{m}$. Further insights into the speed of corrosion in reinforcing bars can be derived by differentiating and inverting Eq. (8) with respect to $\theta$ :

$$
\omega=\frac{\partial \theta}{\partial T_{i}}=\frac{v_{2}^{3} \sqrt{2 \pi}}{v_{1}(180-\theta)} e^{\frac{(\theta-180)^{2}}{2 v_{2}^{2}}}
$$

where $\omega$ could be interpreted to represent the physical quantity, angular velocity (degree/year). In terms of dynamics, $\omega$ explains the velocity of non-structural damage propagation along the surface of the reinforcing bars as chlorides, both spatially and temporally, accumulate over time in response to the impermeable nature of the bars. Note that in Eq. (9) a value of $\theta=0^{\circ}$ leads to a maximum value of $\omega$, which is associated with $T_{i}^{1}$ while $\theta=180^{\circ}$ 
results in an undefined value indicating a presence of discontinuity and is related to $T_{i}^{\max }$ in the case of scheme-I circumstances.

Figure 5 shows the variations in $\omega_{\max }$ for $\mathrm{R}_{\mathrm{c}}$ and $\mathrm{R}_{\mathrm{m}}$ taking into account the effects of $C_{d}$ and $d_{r}$. At equal bar size, the ratios of $\omega_{\max }$ between $R_{c}$ and $R_{m}$ are observed to range from 5.2 to 2.6 , and progressively decrease with the increase in $C_{d}$. Higher values of $\omega_{\max }$ for $\mathrm{R}_{\mathrm{c}}$ in figure 5 indicate a faster build-up of chlorides on the surface of the corner bar when compared with $\mathrm{R}_{\mathrm{m}}$, which is attributed to higher dimensional chloride ingress. The practical implication of these results is that the onset of corrosion-induced structural damages on the concrete cover around a corner bar would be much more critical when compared with those for a middle bar. This has been widely acknowledged in the literature (e.g., [32]). On the contrary, at identical cover depths, $\omega_{\max }$ ratios between $\mathrm{R}_{\mathrm{c}}$ and $\mathrm{R}_{\mathrm{m}}$ are found to fall between 3.2 and 6.3; however, gradually increase with the rise in $d_{r}$. Secondly, in the case of $\mathrm{R}_{\mathrm{m}}$, the values of $\omega_{\max }$ drops with increasing $d_{r}$. The former behavior could be explained as follows. With a rise in $d_{r}$, the distance between the corner of the $\mathrm{RC}$ beam and the potential location for the occurrence of $T_{i}^{1}$ on the surface of $\mathrm{R}_{\mathrm{c}}$ increases and thereby effectively causing an increase in $\omega_{\max }$. With reference to the latter, the cross-sectional area of the obstruction increases with a rise in $d_{r}$ consequently leading to a decrease in the values of $\omega_{\max }$. A useful opinion from this observation is that an increase in $d_{r}$ makes $\mathrm{R}_{\mathrm{m}}$ extremely vulnerable to faster corrosion initiation. This could be additionally verified from table 1 , where it has been shown that a rise in $d_{r}$ decreases $T_{i}^{1}$ in the case of $\mathrm{R}_{\mathrm{m}}$. Such differences in $T_{i}^{1}$ need to be given due attention while

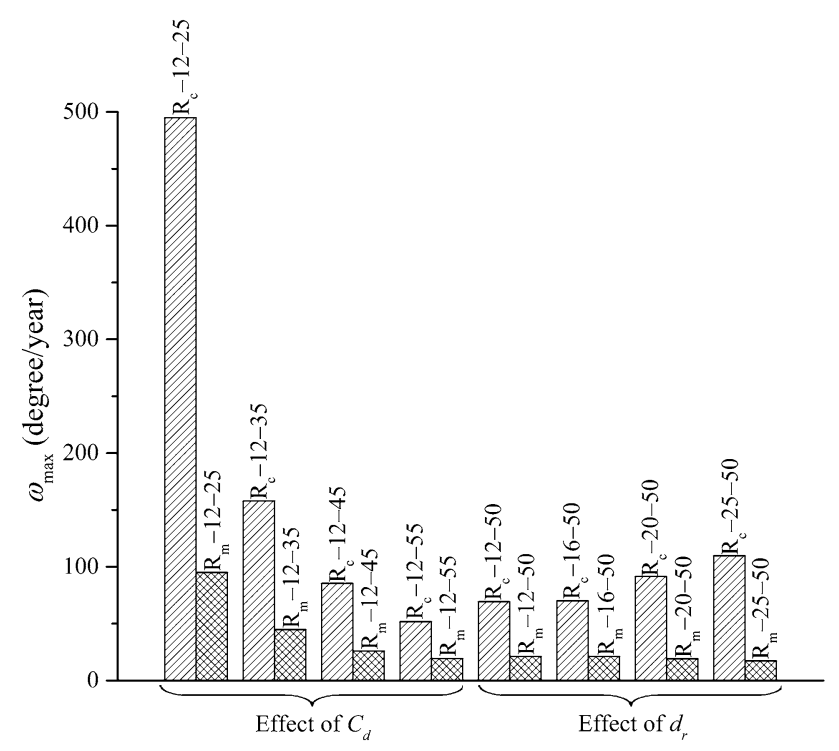

Figure 5. Variations in maximum velocity associated with $T_{i}^{1}$ for $\mathrm{R}_{\mathrm{c}}$ and $\mathrm{R}_{\mathrm{m}}$. integrating strength and serviceability limit states into a failure model. This allows more realistic estimations for the service life of RC structures.

\section{Structural stage of damage}

\subsection{Depth of corrosion penetration}

The depth of corrosion penetration quantifies the loss in steel section, and it is time-variant in nature. At any given time after the first onset of corrosion reaction in the reinforcing bars, the spatial variation in corrosion loss can be estimated by employing Eq. (4) over the known spatial and temporal spreads of non-structural damage. Figures 6(a) and (b) display the spatial spreads of the depths of corrosion penetration along the circumference of the bars pertaining to the simulation variables listed in table 1 after the exposure period of 50 years. The following characteristics of the depth of corrosion penetration can be derived from figures 6(a) and (b): (1) its spread is spatially non-uniform and is either incomplete or complete along the circumference of the bars; (2) the location of occurrence of its maximum value is influenced by the position of steel bars in an RC beam; (3) the extent of its spread along the surface of $R_{c}$ is always larger when compared with that for $\mathrm{R}_{\mathrm{m}}$, and (4) the sizes of bar also affect its propagation. Note that, in the current study, the rate of corrosion is evaluated based on Eq. (5), and hence the estimates of $p_{d}$ are highly dependent on the chosen model of the corrosion rate. Moreover, a practical advantage of $p_{d}$ is that it can provide actual loss in steel cross section, which often can be assessed only by means of a visual inspection.

Depending on the period of exposure after corrosion initiation (i.e., $t$ ), the value of $p_{d}$ is expected to be maximum (i.e., $p_{d}^{\max }$ ) at the location of $T_{i}^{1}$ (see figure 3) and the minimum value of $p_{d}$ (i.e., $p_{d}^{\mathrm{min}}$ ) is likely to fall either at $T_{i}^{\max }$ if $\left(t-T_{i}^{1}\right)>T_{i}^{\max }$ or at any other location on the circumference of the bar having $t-T_{i}^{1}=0$. Under these conditions, a flipped Gaussian form is one of the feasible choices for determining the trends of $p_{d}$ data, and thus the following equation is proposed:

$$
p_{d}(\theta)=\frac{-\chi_{1}}{\chi_{2} \sqrt{2 \pi}} e^{-\frac{(\theta-180)^{2}}{2 \chi_{2}^{2}}}+p_{d}^{\max }
$$

where $\chi_{1}$ and $\chi_{2}$ represent non-linear regression parameters. Note that Eq. (10) represents only the spatial evolution of $p_{d}$ at a single point in time. To estimate the value of regression parameters, standard smooth curve fitting analyses are conducted over the data points of $p_{d}$ concerning the simulation variables shown in figures 6(a) and (b) by employing Eq. (10). Figures 7(a) and (b) display the trend lines based on Eq. (10) superimposed over the data points of $p_{d}$. It could also be noted that the fitting analysis yielded 

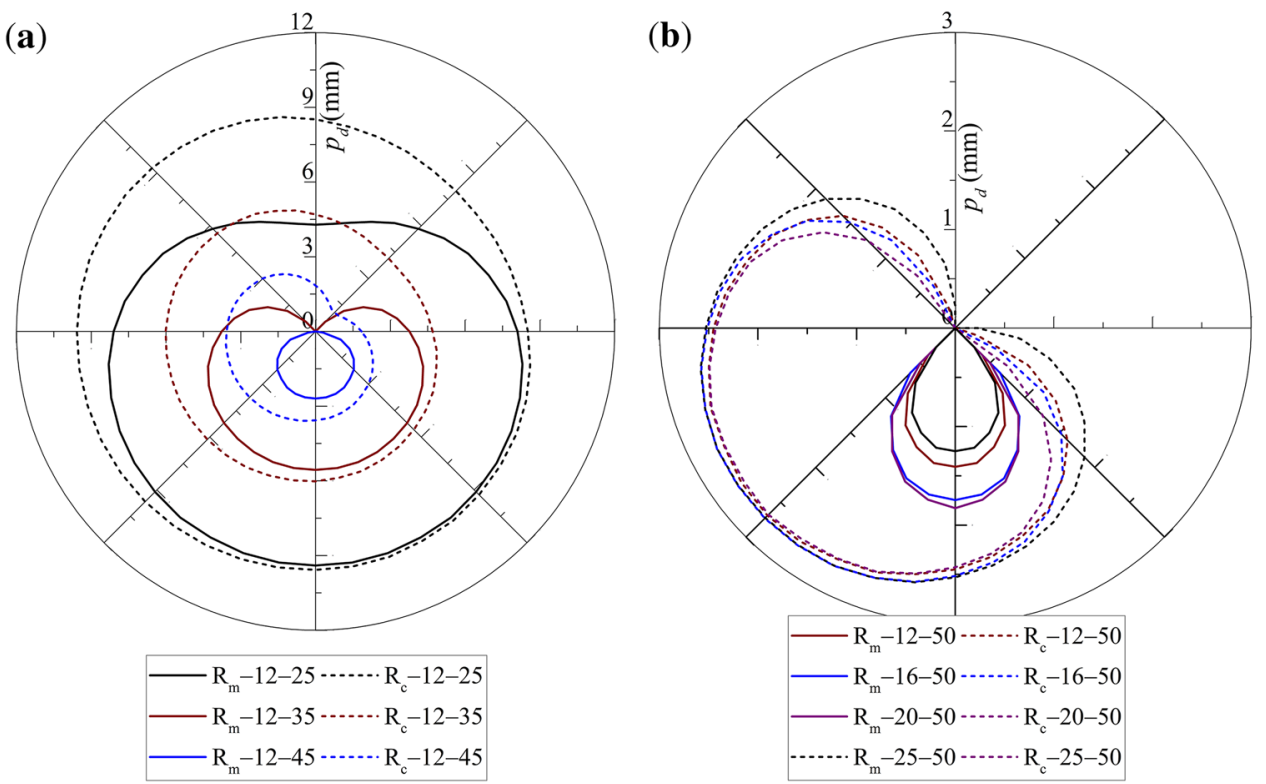

Figure 6. Spatial spread of $p_{d}$ after 50 years of exposure: (a) Effect of $C_{d}$; (b) Effect of $d_{r}$.

(a)

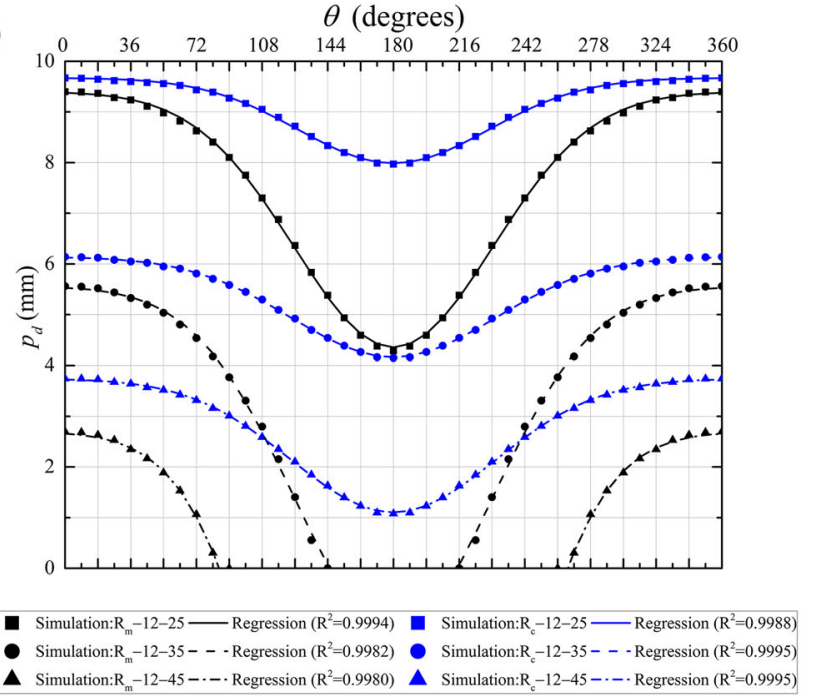

(b)

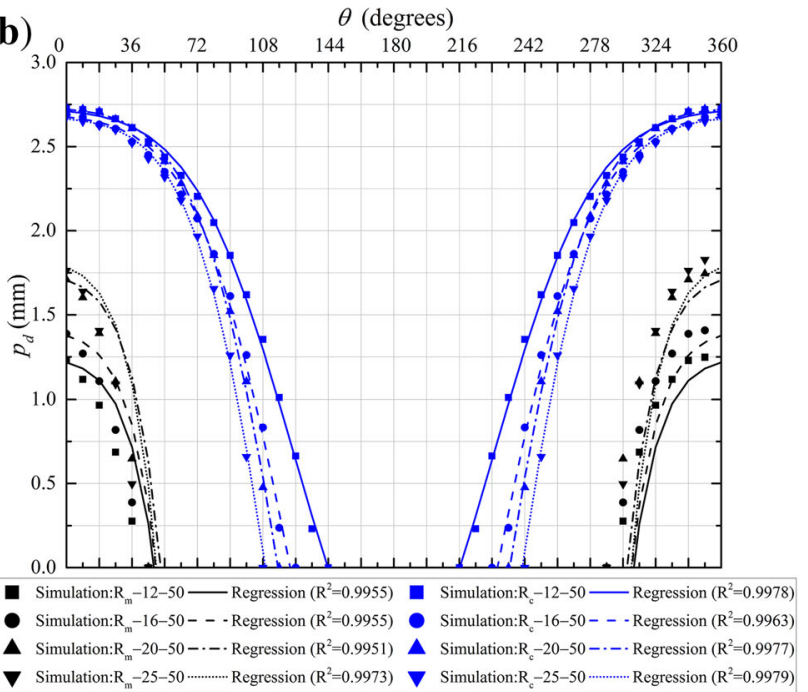

Figure 7. Best-fits of the proposed Gaussian model on the simulation data points of $p_{d}$ after the exposure period of 50 years: (a) Effect of $C_{d}$; (b) Effect of $d_{r}$.

R-Squared values of 0.99 and higher, indicating that the predictions based on Eq. (10) are very close to the values obtained from simulation data.

Further, the values of $\chi_{1}, \chi_{2}, p_{d}^{\max }$ and R-Square obtained from the regression analysis are tabulated in table 2 along with $\theta_{\min }$ and $\theta_{\max }$. As can be noted from figure 7(a) and table 2 , at equal $d_{r}$, the ratios of $p_{d}^{\max }$ between $\mathrm{R}_{\mathrm{c}}$ and $\mathrm{R}_{\mathrm{m}}$ lie between 1.02 and 1.37 implying $p_{d}^{\max }$ for $\mathrm{R}_{\mathrm{c}}$ is higher than that for $R_{m}$ and progressively increase with the rise in $C_{d}$. Additionally, figure 7(a) reveals that the difference in $p_{d}^{\min }$ between $\mathrm{R}_{\mathrm{c}}$ and $\mathrm{R}_{\mathrm{m}}$ could be very substantial. For instance, in the case of a $p_{d}$ fully spread (e.g., $\mathrm{R}_{\mathrm{c}} / \mathrm{R}_{\mathrm{m}}-12-$
25) along the circumference of the bar, the change in $p_{d}^{\min }$ between $R_{c}$ and $R_{m}$ is estimated to be $84 \%$. This important finding reveals that, at equal bar size, the corner bars incur severe non-uniform corrosion loss when compared with that for middle bars. Further, at similar cover depths, the influence of $d_{r}$ on $p_{d}$ indicates that the extent of $p_{d}$ along $R_{c}$ changes whereas it remains the same along $R_{m}$. Whereas $p_{d}^{\max }$ is observed to rise with a gain in bar size in the case of $R_{m}$ while it is almost a constant for $R_{c}$. Such observation reiterates the fact that the structural damages in the concrete cover are highly influenced by bar sizes, specifically $R_{m}$. 
Table 2. Values of $\chi_{1}$ and $\chi_{2}$ obtained from regression analysis of $p_{d}$ data.

\begin{tabular}{|c|c|c|c|c|c|c|c|c|c|c|}
\hline \multirow[b]{2}{*}{ Variable } & \multicolumn{2}{|c|}{$\begin{array}{l}p_{d}^{\max } \\
(\mathrm{mm})\end{array}$} & \multicolumn{2}{|c|}{$\chi_{1}$} & \multicolumn{2}{|c|}{$\chi_{2}$} & \multicolumn{2}{|c|}{$\mathrm{R}^{2}$} & \multicolumn{2}{|c|}{$\begin{array}{c}\theta_{\min }, \theta_{\max } \\
\text { (degrees) }\end{array}$} \\
\hline & $X=R_{c}$ & $X=R_{m}$ & $X=R_{c}$ & $\mathrm{X}=\mathrm{R}_{\mathrm{m}}$ & $X=R_{c}$ & $\mathrm{X}=\mathrm{R}_{\mathrm{m}}$ & $X=R_{c}$ & $\mathrm{X}=\mathrm{R}_{\mathrm{m}}$ & $X=R_{c}$ & $\mathrm{X}=\mathrm{R}_{\mathrm{m}}$ \\
\hline$X-12-25$ & 9.6 & 9.4 & 220.00 & 690.32 & 52.17 & 54.55 & 0.9988 & 0.9994 & - & - \\
\hline$X-12-35$ & 6.1 & 5.5 & 277.96 & 936.13 & 56.14 & 54.73 & 0.9995 & 0.9982 & - & 144,216 \\
\hline$X-12-45$ & 3.7 & 2.7 & 371.93 & 1889.47 & 56.19 & 52.04 & 0.9995 & 0.9980 & - & 81,279 \\
\hline$X-12-50$ & 2.7 & 1.2 & 465.52 & 9900.93 & 54.79 & 45.07 & 0.9978 & 0.9955 & 144,216 & 45,315 \\
\hline$X-16-50$ & 2.7 & 1.4 & 636.67 & 10265.95 & 53.09 & 45.13 & 0.9963 & 0.9955 & 126,234 & 45,315 \\
\hline$X-20-50$ & 2.7 & 1.7 & 761.62 & 9759.345 & 50.92 & 45.84 & 0.9977 & 0.9951 & 117,243 & 45,315 \\
\hline$X-25-50$ & 2.7 & 1.8 & 897.86 & 11928.16 & 50.72 & 45.74 & 0.9979 & 0.9973 & 108,252 & 45,315 \\
\hline
\end{tabular}

To validate the Gaussian behaviour in the spatial spread of $p_{d}$, experimental data on the corrosion layer thickness reported in [21,33] are considered. The onset of corrosion reaction in the reinforcing bar leads to the formation of corrosion products whose volume is higher than the active steel [34]. Under this consideration, $p_{d}$ times the volume expansion rate of the corrosion products could be assumed to represent potentially the thickness of the corrosion layer. It is worthy to note here that, in RC under natural exposure, the volume expansion rate is not a constant, but varies depending on local conditions, humidity, and oxygen availability [35]. Moreover, accurate evaluation of the spread of $p_{d}$ along the bar, in general, is possible only after extraction of the steel from the concrete specimens; however, it has been shown (e.g., [21, 33]) that the thickness of corrosion layer could be measured during the progression of corrosion by using advanced techniques, for example, digital microscopy. For comparison purposes, three test results from [33] (i.e., YJ\&M 1-3) and two experimental data from [21] (i.e., ZHY\&J 1 and ZHY\&J 2) are chosen. Note that among the five data set, four are associated with situations similar to $R_{m}$ type of exposure while the fifth one namely, ZHY\&J 2 is similar to $\mathrm{R}_{\mathrm{c}}$ kind of exposure.

Figures 8(a) and (b) show the trend lines over the data points reported in $[21,33]$ based on the proposed Gaussian model (i.e., Eq. (10)). Note that the Gaussian curves shown in figures 8(a) and (b) are standard whereas they are flipped in figures 7(a) and (b). This is because the value of polar coordinate $\theta$, at the location of maximum corrosion layer thickness, is taken as $180^{\circ}$ in figures $8(a)$ and (b), as opposed to $0^{\circ}$ in figures 7 (a) and (b), so as to match the axis representations in $[21,33]$. With this change in $\theta$, the value of minimum corrosion layer thickness replaces $p_{d}^{\max }$ in Eq. (10), and the minus sign in $\chi_{1}$ is also dropped. Moreover, in the present work, this change in the value of $\theta$ does not affect the nature of the trend lines, that is, Gaussian behaviour, and is applicable only to figures $8(a)$ and (b). As shown in table 3 and figures 8(a) and (b), the trend lines over the corrosion layer thickness data have a greater affinity for the Gaussian function. A similar information that the spatial spread of corrosion layer thickness follows Gaussian model can also be found in [21, 33]. Moreover, it can also be observed from figure 8(b) that the thickness of the corrosion layer is relatively high in the case of ZHY\&J 2 (i.e., for a corner bar) when compared with that of ZHY\&J 1 (i.e., for a middle bar) thus experimentally confirming the higher corrosion damage vulnerability of concrete cover in the region of a corner bar than that of a middle bar.
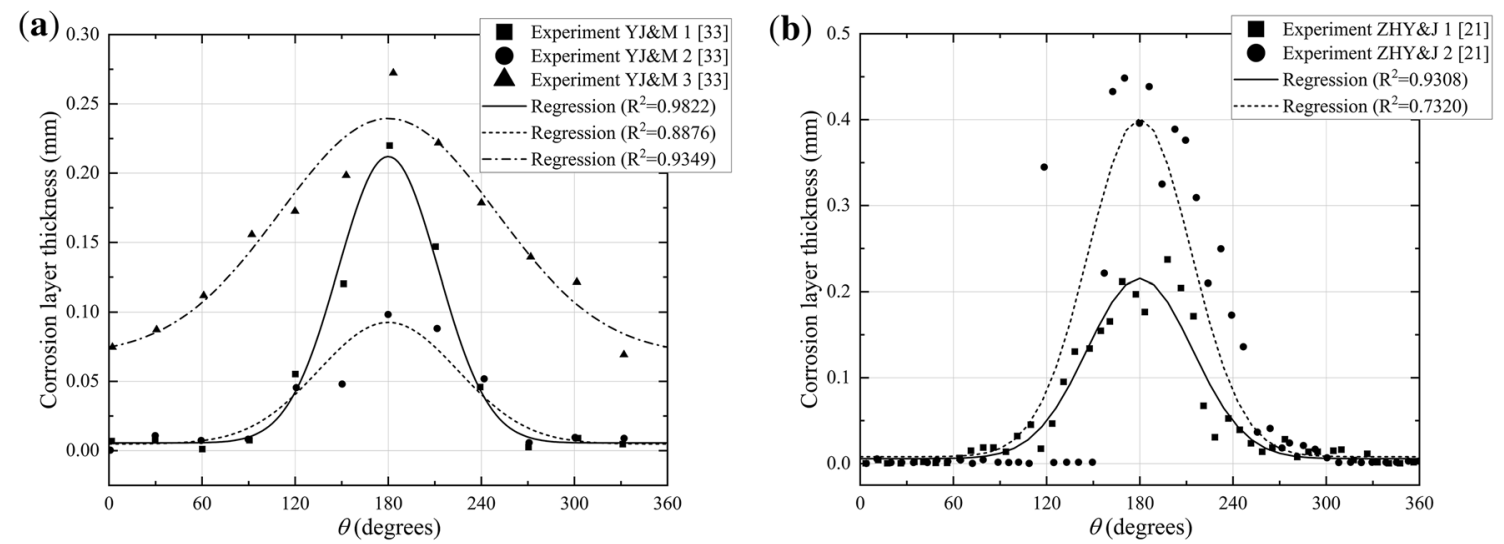

Figure 8. Regression analysis of the proposed Gaussian model over the experimental data [21, 33] of corrosion layer thickness. 
Table 3. Values of $\chi_{1}$ and $\chi_{2}$ obtained from regression analysis of experimental data of corrosion layer thickness.

\begin{tabular}{|c|c|c|c|c|}
\hline Specimen & $\begin{array}{c}\text { Minimum } \\
\text { corrosion layer } \\
\text { thickness }(\mathrm{mm})\end{array}$ & $\chi_{1}$ & $\chi_{2}$ & $\mathrm{R}^{2}$ \\
\hline YJ\&M 1 [34] & 0.0055 & 16.69 & 32.27 & 0.9822 \\
\hline YJ\&M 2 [34] & 0.0048 & 9.85 & 44.80 & 0.8876 \\
\hline YJ\&M 3 [34] & 0.0688 & 29.66 & 69.34 & 0.9349 \\
\hline ZHY\&J 1 [23] & 0.0057 & 17.80 & 33.88 & 0.9308 \\
\hline ZHY\&J 2 [23] & 0.0080 & 32.61 & 33.06 & 0.7320 \\
\hline
\end{tabular}

\subsection{Variation in bar size}

The non-uniform corrosion loss of steel leads to a severe reduction in diameter of reinforcing bars. Figures 9(a) and (b) display the spatial distribution of corrosion loss along the circumference of the reinforcing bars, in terms of diameter reduction $d_{c r}(\mathrm{~mm})$, for the simulation variables shown in figures 6(a) and (b). Note that $d_{c r}$ is evaluated by subtracting the spatial spread of $p_{d}$ from $d_{r}$. It can be verified that, for completeness, corrosion loss is higher for the corner bars than that for the middle bars. From figures 6(a) and (b), based on the patterns of the corroded bars, two different types of non-uniform corrosion morphologies of the reinforcing bars can be characterized, namely morphology-I and morphology-II (see figures 10(a) and (b)). Morphology-I and morphology-II correspond to patterns of corroded bars where the corrosion losses are uneven and are either spread partly or entirely along the circumference of the reinforcing bar, respectively. With regard to the corrosion loss and its influence on strength and serve ability limit states, morphology-I could be considered to be more server that that due to morphology-II. Further, as could be noticed from figure 10(a), the spatial spread of $p_{d}$ has a uniform component equal to $p_{d}^{\min }$ and a non-uniform component equal to the difference between $p_{d}^{\max }$ and $p_{d}^{\min }$ in the case of morphology-I whereas morphology-II has only the non-uniform component equal to $p_{d}^{\max }$. Moreover, in figures 10(a) and (b), $d_{c r}^{\min }$ and $d_{c r}^{\max }$ represent minimum and maximum reinforcing bar diameters $(\mathrm{mm})$, respectively.

To determine the trends in spatial variations of $d_{c r}$ along the surface of the bar, once again, a Gaussian form is adopted as follows:

$$
d_{c r}=\frac{\chi_{1}}{\chi_{2} \sqrt{2 \pi}} e^{-\frac{(\theta-180)^{2}}{2 \chi_{2}^{2}}}+d_{c r}^{\min }
$$

where the values of $\chi_{1}, \chi_{2}$ and R-Square are the same as indicated in table 2. Additionally, the corresponding estimates for $d_{c r}^{\min }$ can be obtained by subtracting the values of $p_{d}^{\max }$ in table 2 from their respective $d_{r}$. Figures 11(a) and (b) show regression analysis illustrating the relationship between Eq. (11) and the data points of $d_{c r}$. It can be observed that the trends of corrosion morphologies I and II are more consistent with the Gaussian form.

To validate that the patterns of corroded bars under natural chloride environment have the potential to follow the Gaussian model in Eq. (11), macroscopic specimens reported in [23] are considered. This study reported the changing shapes of the corroded steel bars extracted from concrete walls under natural exposure for a period of 35 years. For validation purposes $d_{c r}$ data of four specimens (L\&L 1-4) reported in [23] are subjected to regression analysis based on Eq. (11). Figures 12(a)-(d) show the trend lines drawn over the data points of $d_{c r}$, and table 4 gives the values of regression parameters obtained from the

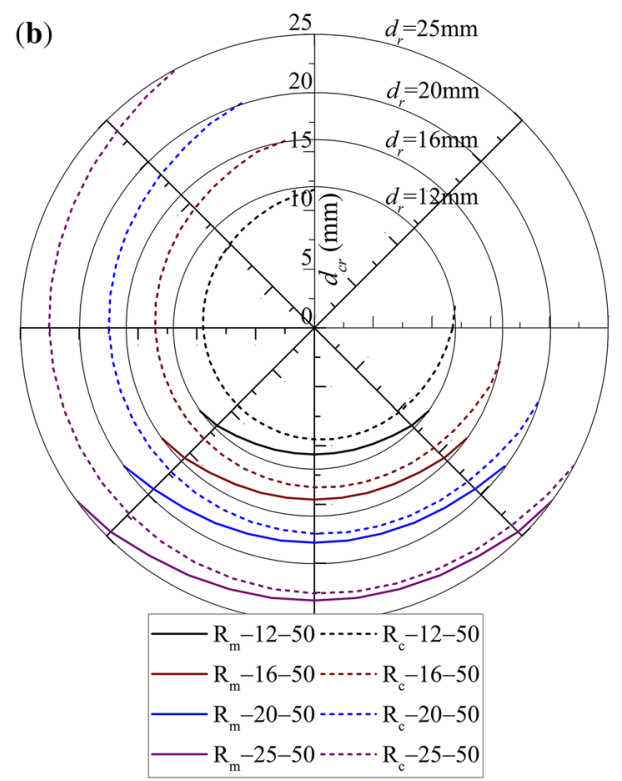

Figure 9. Spatial distribution of corrosion loss after 50 years of exposure: (a) Effect of $C_{d}$; (b) Effect of $d_{r}$. 
(a)

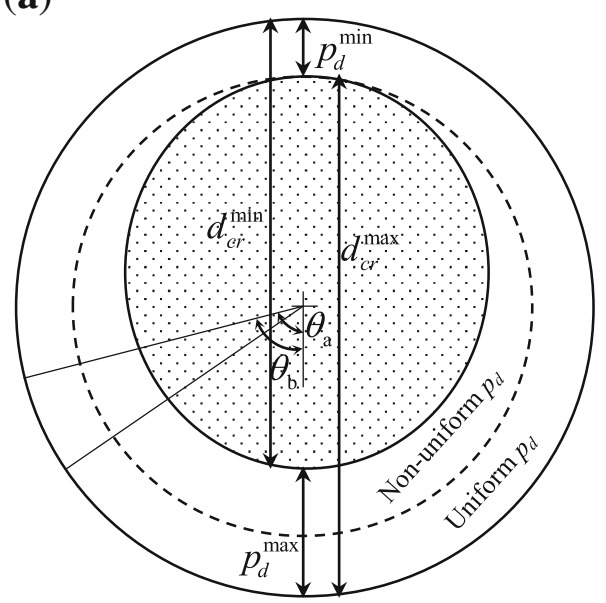

(b)

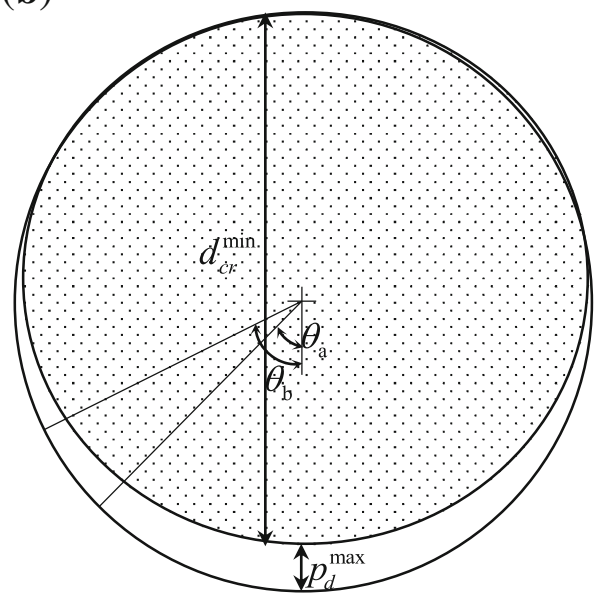

Figure 10. Classification of corrosion patterns: (a) Morphology-I; (b) Morphology-II.

(a)

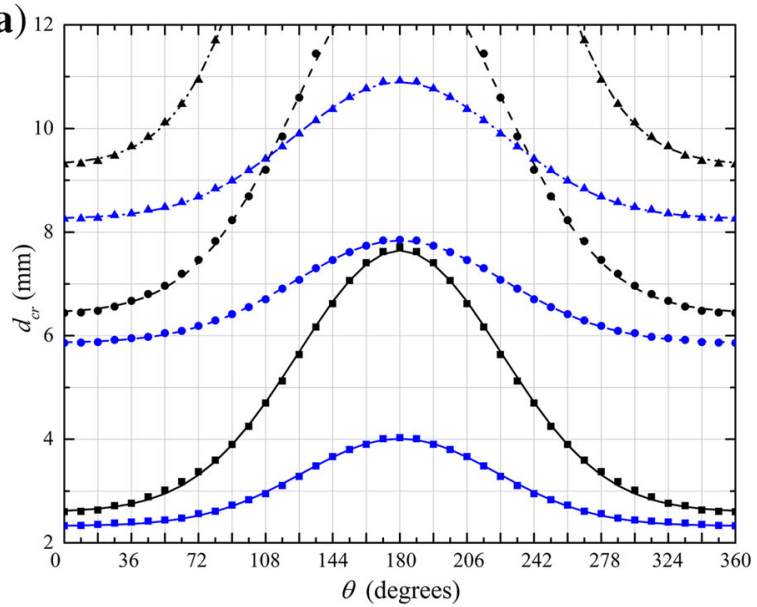

- Simulation: $\mathrm{R}_{\mathrm{m}}-12-25-$ Regression $\left(\mathrm{R}^{2}=0.9994\right)$

- Simulation: $\mathrm{R}_{\mathrm{m}}-12-35$ - - - Regression $\left(\mathrm{R}^{2}=0.9982\right)$

- Simulation: $\mathrm{R}_{\mathrm{m}}-12-45-\cdot-\cdot \cdot$ Regression $\left(\mathrm{R}^{2}=0.9980\right)$ (b)

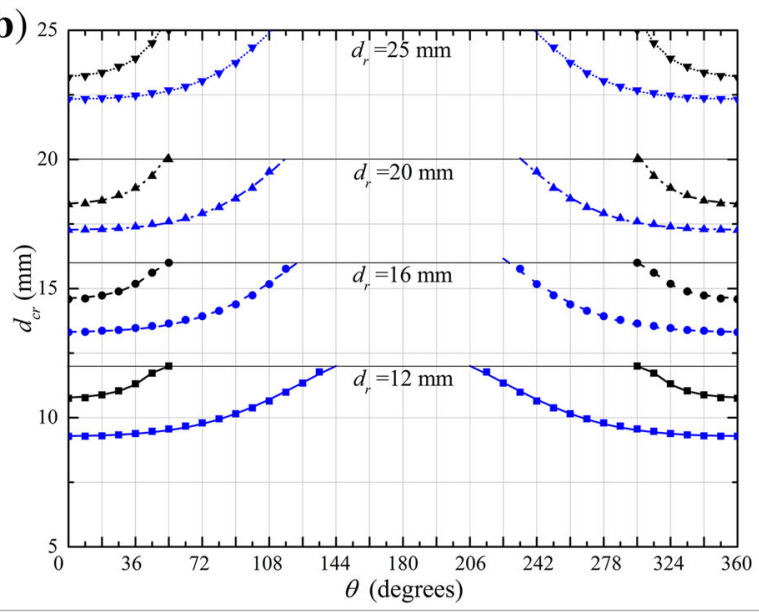

Simulation: $R-12-50-$ Regression $\left(R^{2}=0.9955\right)$ Simulation: $R-12-50-R$ Regression $\left(R^{2}=0.9978\right)$

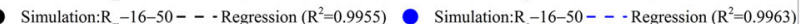
- Simulation $: R_{m}-20-50-\cdot-\cdot R$ Regression $\left(R^{2}=0.9951\right) \Delta$ Simulation: $R_{c}-20-50-\cdot-\cdot R$ Regression $\left(R^{2}=0.9977\right)$ $\boldsymbol{\nabla}$ Simulation: $\mathrm{R}_{\mathrm{m}}-25-50 \cdots \cdots \cdots \cdots$. Regression $\left(\mathrm{R}^{2}=0.9973\right) \boldsymbol{\nabla}$ Simulation: $\mathrm{R}_{\mathrm{c}}-25-50 \cdots \cdots \cdots \cdots$ Regression $\left(\mathrm{R}^{2}=0.9979\right)$

Figure 11. Regression analysis of the relationship between the Gaussian model and the simulation data points of $d_{c r}$ after 50 years: (a) Effect of $C_{d}$; (b) Effect of $d_{r}$.

regression analysis. Amongst the four specimens, L\&L 1-3 were observed to fit in with morphology-I while L\&L 4 was found to follow morphology-II. Nonethless, as can be observed from table 4 , all the four macroscopic specimens data are very consistent with the Gaussian form.

\section{Numerical inverse analysis}

This section introduces a potential approach for the prediction of spatial and temporal variations in $T_{i}$ by numerical inverse analysis from an experimentally observed spatial spread of $p_{d}$. For instance, if a spatial distribution of $p_{d}$, in any visually inspected specimen, has been ascertained to have a Gaussian trend similar to Eq. (10), then it can be potentially related to the Gaussian behaviour of the spatially and temporary varying non-structural damage. One way to mathematically model this relationship is to substitute Eq. (8) and Eq. (5) into Eq. (4):

$$
p_{d}(t)=\frac{1.6360}{C_{d}}\left(\left[t-T_{i}^{1}\right]-\frac{v_{1}}{v_{2} \sqrt{2 \pi}} e^{-\frac{(\theta-180)^{2}}{2 v_{2}^{2}}}\right)^{0.71}
$$

where $p_{d}(t)$ indicates the variation in corrosion penetration depth as a function of time. The right-hand side of the Eq. (12) has three unknowns namely $T_{i}^{1}, v_{1}$ and $v_{2}$; hence, 
(a)

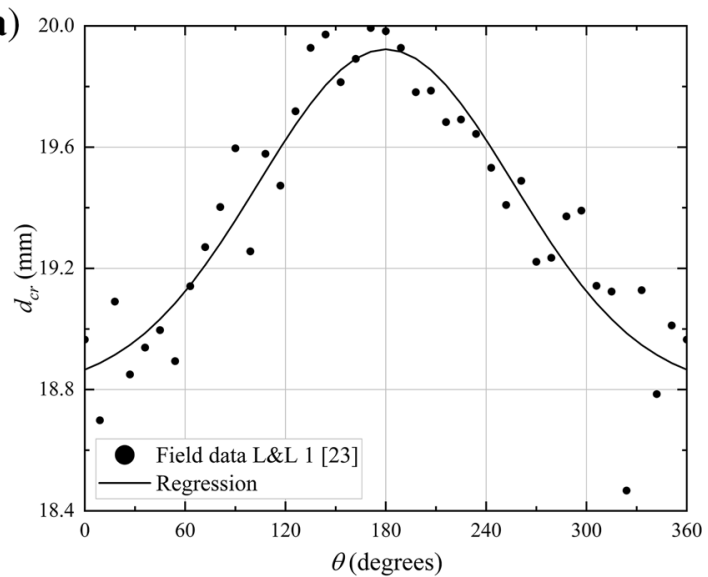

(c)

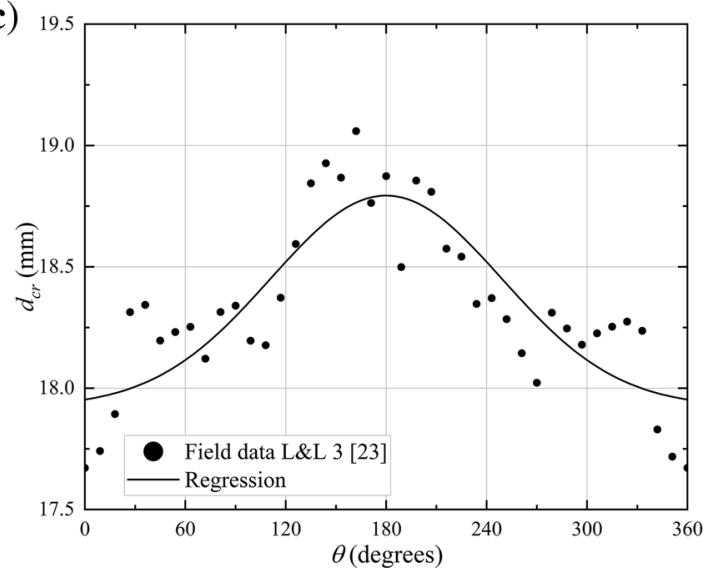

(b)

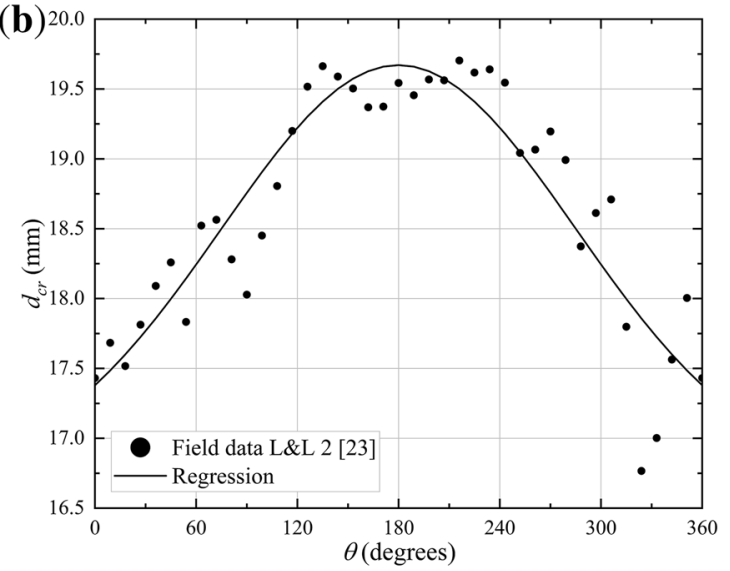

(d)

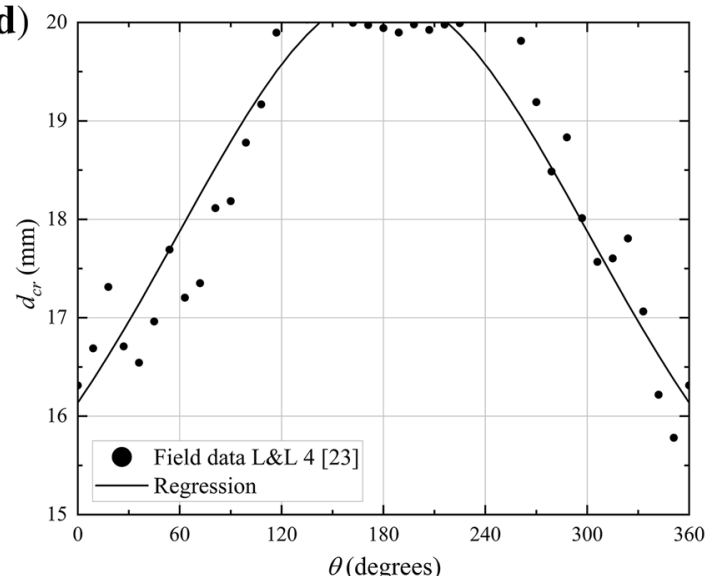

Figure 12. Regression analysis of the proposed Gaussian model over the experimental data [23] of $d_{c r}$.

Table 4. Values of $\chi_{1}$ and $\chi_{2}$ obtained from regression analysis of field data [23] of $d_{c r}$.

\begin{tabular}{lcrrc}
\hline Specimen & $d_{c r}^{\min }(\mathrm{mm})$ & \multicolumn{1}{c}{$\chi_{1}$} & \multicolumn{1}{c}{$\chi_{2}$} & $\mathrm{R}^{2}$ \\
\hline L\&L 1 & 18.79 & 215.98 & 76.42 & 0.8670 \\
L\&L 2 & 16.69 & 784.26 & 105.07 & 0.8354 \\
L\&L 3 & 17.92 & 150.60 & 69.05 & 0.7168 \\
L\&L 4 & 14.09 & 1875.45 & 120.76 & 0.9089 \\
\hline
\end{tabular}

for a given variation of $p_{d}$, three boundary conditions would be required to find their values. The possible boundary conditions are:

$$
\begin{aligned}
& p_{d}=p_{d}^{\max } @ \theta=0 \\
& p_{d}=p_{d}^{a} @ \theta=\theta_{a} \\
& p_{d}=p_{d}^{b} @ \theta=\theta_{b}
\end{aligned}
$$

where $p_{d}^{a}$ and $p_{d}^{b}$ are the depths of corrosion penetration at $\theta_{a}$ and $\theta_{b}$ (in degrees), respectively (see figures 10(a) and (b)). From Eq. (13) $T_{i}^{1}$ can be directly determined and then by back substituting $T_{i}^{1}$ into Eqs. (14) and (15) $v_{1}$ and $v_{2}$ can be obtained by solving the equations for real roots:

$$
\begin{aligned}
T_{i}^{1} & =t-\left(\frac{p_{d}^{\max } \times C_{d}}{1.6360}\right)^{\frac{1}{0.71}} \\
v_{1} & =A\left(\frac{B}{A}\right)^{\frac{\left(\theta_{a}-180\right)^{2}}{\left(\theta_{b}-\theta_{a}\right)\left(\theta_{b}-360+\theta_{a}\right)}} \sqrt{\frac{\pi\left(\theta_{a}^{2}-\theta_{b}^{2}\right)+360 \pi\left(\theta_{b}-\theta_{a}\right)}{\ln \left(\frac{B}{A}\right)}} \\
v_{2} & =\frac{1}{\sqrt{2 \pi}} \sqrt{\frac{\pi\left(\theta_{a}^{2}-\theta_{b}^{2}\right)+360 \pi\left(\theta_{b}-\theta_{a}\right)}{\ln \left(\frac{B}{A}\right)}}
\end{aligned}
$$

Where

$$
\begin{aligned}
& A=t-T_{i}^{1}-\left(\frac{p_{d}^{a} \times C_{d}}{1.6360}\right)^{\frac{1}{0.71}} \\
& B=t-T_{i}^{1}-\left(\frac{p_{d}^{b} \times C_{d}}{1.6360}\right)^{\frac{1}{0.71}}
\end{aligned}
$$

The steps involved in the numerical analysis are (1) evaluate $T_{i}^{1}$ from Eq. (16) with the known values of $p_{d}^{\max }$ 
and $C_{d}$, (2) determine $p_{d}^{a}$ and $p_{d}^{b}$ at any two locations, $\theta_{a}$ and $\theta_{b}$, along the surface of the bar, (3) estimate $A$ and $B$ from Eqs. (19) and (20), and (4) calculate $v_{1}$ and $v_{2}$ from Eqs. (17) and (18). For illustration purposes, the numerical inverse analysis is performed by using the regression data (see table 4) of the four field specimens (L\&L 1-4) reported in [23]. To conduct the analyses, the value of cover depth is assumed (not reported in [23]) to be $25 \mathrm{~mm}$, and the values of $\theta_{a}$ and $\theta_{b}$ are considered to be $20^{\circ}$ and $30^{\circ}$, respectively. The values of $T_{i}^{1}, v_{1}$ and $v_{2}$ obtained through numerical inverse analysis are given in table 5, and figure 13 displays the possible Gaussian distribution of non-structural damages along the circumference of the reinforcing bars based on table 5 .

From the inverse analysis, ratios between $T_{i}^{1}$ and $T_{i}^{\max }$ are obtained as 1.07, 1.70, 1.10, and 6.09 for the four cases L\&L 1-4, respectively. It can be observed from figure 13 that the spatial and temporal variations of non-structural damage for L\&L 1 and L\&L 3 are very flatter with only $7 \%$ and $10 \%$ increments from their respective minimum values. Such smaller increments indicate faster nature of the damage evolutions. A likely reason for this behaviour could be (1) presence of wider cracks in the cover concrete and/or (2) lower quality of cover concrete, which is attributed to poor workmanship. Both of these reasons have a high

Table 5. Values of $T_{i}^{1}, v_{1}$ and $v_{2}$ obtained from numerical inverse analysis.

\begin{tabular}{lcrc}
\hline Regression data & $T_{i}^{1}$ (years) & \multicolumn{1}{c}{$v_{1}$} & $v_{2}$ \\
\hline L\&L 1 & 32.6 & 548.76 & 77.78 \\
L\&L 2 & 25.2 & 2904.21 & 63.15 \\
L\&L 3 & 29.9 & 505.79 & 61.39 \\
L\&L 4 & 12.8 & 8493.62 & 51.22 \\
\hline
\end{tabular}

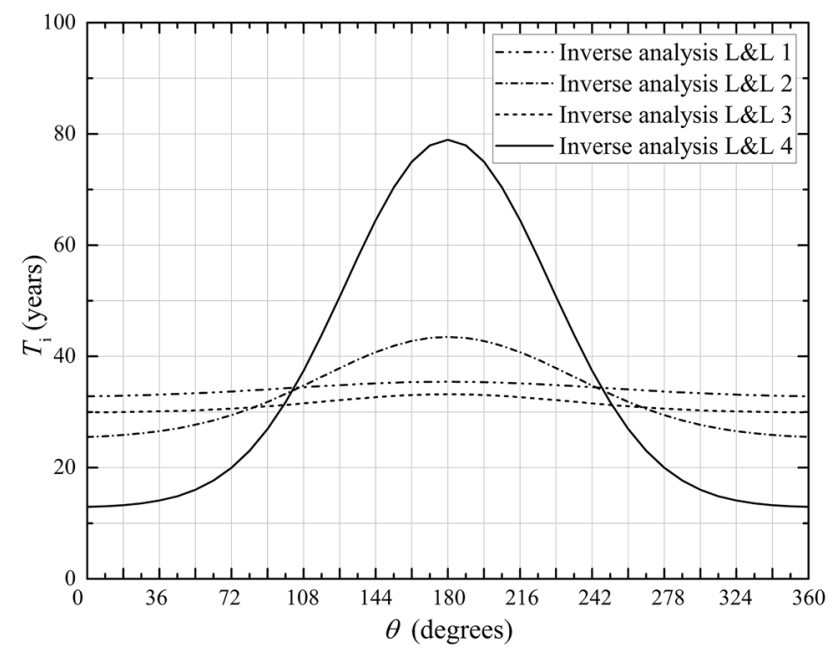

Figure 13. Gaussian distribution of non-structural damage obtained from numerical inverse analysis. potential to enhance chloride ingress leading to much quicker depassivation. Additionally, the flatter nature also suggests that the transformation of steel into rust occurs along the entire surface of the bar within a short period of time. On the contrary, curves related to L\&L 2 and L\&L 4 have well-developed peaks indicating not only the development of severe corrosion on part of the steel surface but also a presence of high degree of non-uniform component under such circumstances.

The introduced numerical inverse analysis poses a promising approach for predicting the possible future progressions in both non-structural and structural stages of damage. Such information is invaluable for engineers and decision-makers to ensure the safety of RC structures while reducing the associated intevention costs. Note that the outcome of the analysis is very much dependent on corrosion rate model adopted in the approach. It can also be speculated that the numerical inverse analysis could be used to trace back the non-structural propagation in damage, either analytically or numerically, for any given spatial spread of $p_{d}$ provided $p_{d}$ follows a mathematical expression. It needs to be pointed out here that the performance of the inverse analysis procedure needs to be further rigorously investigated by considering more laboratory and onsite data for realizing its full potential. This topic is suggested for further study.

\section{Validation of superposition approach}

The spatial distribution of tensile stresses developed around steel-concrete interface as a result of corrosion would more or less vary similar to the spatial spread of either the depth of corrosion penetration or the corrosion layer thickness. In recent years, there have been attempts (e.g., [32]) to adopt the superposition approach, which evaluates the spatial distribution of corrosion-induced stresses around the surface of a corner bar exposed to chlorides on two of its adjacent faces (say left and bottom) as a superposition of stresses around the surfaces of two middle bars each exposed to chlorides on different faces of the concrete (say one on the left and another at the bottom). This section aims to, both numerically and experimentally, validate the application of superposition principle. Figures 14(a) and (b) show the comparison of $d_{c r}$ between numerical simulation and superposition approach after 50 years. Note that the simulation results shown in figures 14(a) and (b) (plotted with dotted lines) are the same as presented for $R_{c}$ in figures 9(a) and (b) while data related to superposition (plotted with solid lines) are obtained by adding the actual and the rotated (by $90^{\circ}$ clock-wise) spreads of $R_{m}$ displayed in figures 9(a) and (b).

As shown in figure 14(a), for the variable $R_{c}-12-35$, the values of $p_{d}^{\max }$ based on simulation and superposition are $4.33 \mathrm{~mm}$ and $10.38 \mathrm{~mm}$, respectively, which suggests 


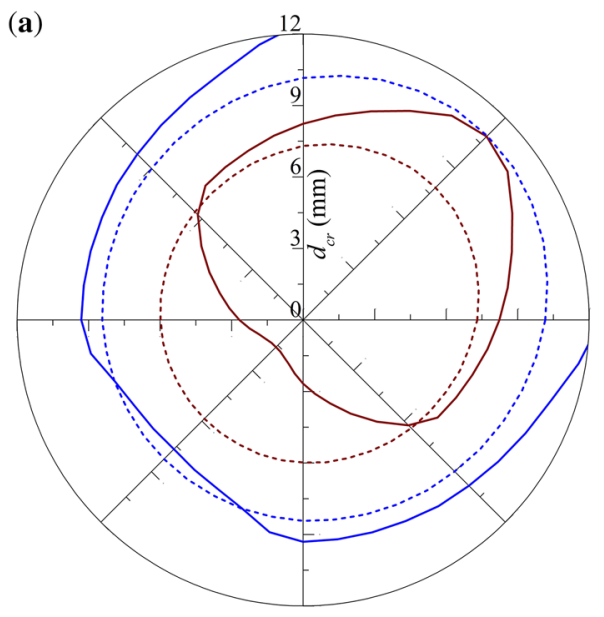

Superposition: $R_{m}-12-35 \cdots-\cdots \cdot$ Simulation: $R_{c}-12-35$ Superposition: $R_{m}-12-45 \cdots \cdots$ Simulation: $R_{c}-12-45$ (b)

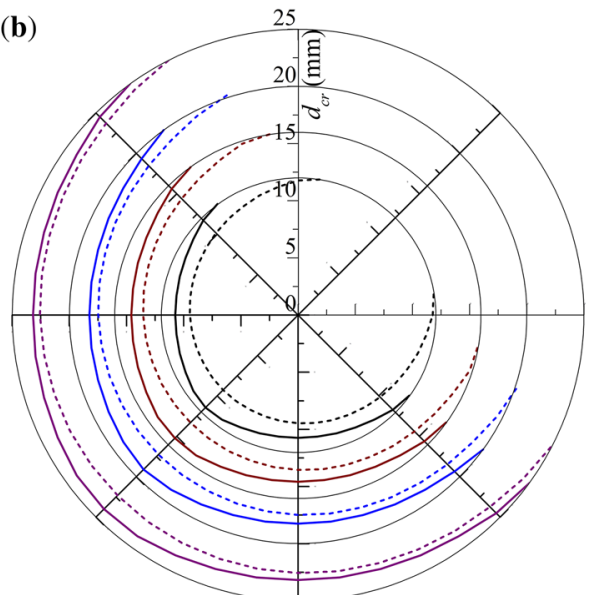

Superposition: $\mathrm{R}_{\mathrm{m}}-12-50$-.-.-. Simulation: $\mathrm{R}_{\mathrm{c}}-12-50$

Superposition: $R_{m}-16-50$-.... Simulation: $R_{c}-16-50$

Superposition: $R_{m}-20-50 \cdots-$ Simulation: $R_{c}-20-50$

Superposition: $R_{m}-25-50 \cdots-\cdots$ Simulation: $R_{c}-25-50$

Figure 14. Comparison of $d_{c r}$ between numerical simulation and superposition approach after 50 years: (a) Effect of $C_{d}$; (b) Effect of $d_{r}$.

an overestimation of $p_{d}^{\max }$ by $69 \%$ based on superposition approach. Additionally, the spatial spread of $p_{d}$ based on superposition is entirely different from that evaluated by simulation. With regard to $R_{c}-12-45$, superposition not only overvalues $p_{d}^{\max }$ by 1.16 times but also leads to a partial spread in $p_{d}$. On the contrary, the results based on the effects of $d_{r}$ on superposition (see figure 14(b)) reveal that the values of $p_{d}^{\max }$ are underestimated by superposition in the range of $7-23 \%$ compared to that calculated by simulation. Moreover, the extent of spreads of $p_{d}$ along the circumferences of the bars are lower in the case of superposition.

Further, to validate the applicability of superposition approach, trend lines for the corrosion layer thickness (see figure 8(b)) for the experimental data ZHY\&J 1 and ZHY\&J 2 [23] are considered. Note that corrosion layer thickness data of ZHY\&J 1 and ZHY\&J 2 correspond to slices of steel bars taken from the middle and corner bars of an RC beam, respectively. Figure 15 displays trend line of ZHY\&J 2 along with the superposed regression line obtained by adding the original and the rotated trend lines of ZHY\&J 1. It is observed that the superposition undervalues maximum corrosion layer thickness by 2.18 times. Hence, as demonstrated in figures 14 and 15, the general applicability of the superposition approach is questionable as it could (1) provide over- or underestimates of maximum tensile stresses around the steel-concrete interface of a corner bar, (2) lead to spatially either higher or lower spread of corrosion-induced stresses along the circumference of a corner bar compared to the actual, (3) potentially misidentify the spatial location for the maximum tensile stress around a corner bar perimeter, and (4) introduce possible spatial and temporal errors while evaluating

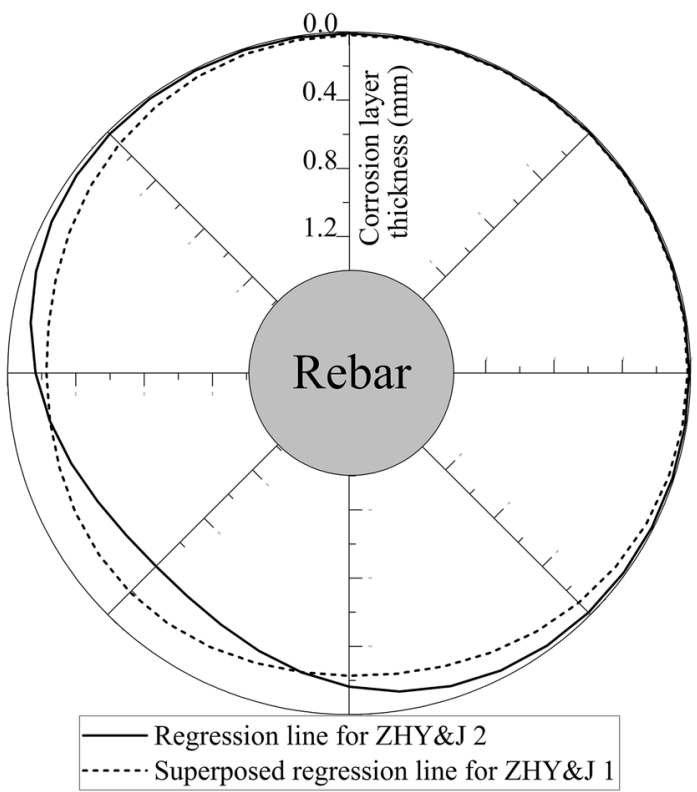

Figure 15. Comparison of corrosion layer thickness based on experimental regression with superposition regression.

structural damages viz, concrete cover cracking, delamination, and spalling. Furthermore, as shown in figure 14(b), for the given combination of cover depth and bar diameter, the superposition approach could provide estimates very close to the actual at certain levels of corrosion damage; however, may not be comparable at all levels. Therefore, some caution is required while applying superposition principle to estimate the spatial variation in corrosion-induced stresses in a corner reinforcing bar. 


\section{Conclusion}

The RC structures vulnerable to chloride-induced corrosion potentially experience two stages of damage, namely nonstructural and structural. The space-time propagations of non-structural damage are categorized into two schemes: scheme-I and scheme-II. A Gaussian function is found to be more appropriate to describe non-structural damage evolutions along steel bar perimeters under both scheme-I and scheme-II cases. Moreover, the spatial spread in corrosion loss of steel bars is quantified in terms of corrosion penetration depth taking into account the space-time propagation in non-structural damage and observed to have greater affinity for yet another Gaussian model. Further, based on the patterns of the corroded bars, two different types of nonuniform corrosion morphologies of the reinforcing bars are characterized, namely morphology-I and morphology-II, and are also observed to follow a Gaussian trend. A new numerical inverse analysis approach is introduced for the prediction of space-time variations in corrosion initiation from an experimentally observed spatial spread of corrosion penetration depth. Finally, the superposition approach, which evaluates the spatial distribution of corrosion-induced stresses around the surface of a corner bar as a superposition of stresses around the surfaces of two middle bars each exposed to chlorides on different faces of the concrete is explored and shown to introduce spatial and temporal errors while evaluating structural damage procedures.

\section{Acknowledgement}

The support of Endeavour Research Fellowship from the Australian Government, Department of Education and Training is gratefully acknowledged.

$\begin{array}{ll}\text { Nomenclature } \\ C_{d} \quad \text { cover depth }(\mathrm{cm}) \\ d_{r} \quad \text { diameter of the original rebar }(\mathrm{mm}) \\ d_{c r} & \text { corroding rebar diameter }(\mathrm{mm}) \\ d_{c r}^{\min } & \text { minimum diameter of the corroding rebar }(\mathrm{mm}) \\ D_{c, \text { Ref }} & \text { reference chloride diffusion coefficient }\left(\mathrm{m}^{2} / \mathrm{s}\right) \\ H_{e n v} & \text { relative humidity in the environment } \\ i_{\text {corr }} & \text { corrosion rate }\left(\mu \mathrm{A} / \mathrm{cm}^{2}\right) \\ p_{d} & \text { corrosion penetration depth }(\mathrm{mm}) \\ p_{d}^{a} & \text { corrosion penetration depth at } a(\mathrm{~mm}) \\ p_{d}^{b} & \text { corrosion penetration depth at } b(\mathrm{~mm}) \\ p_{d}^{\min } & \text { minimum corrosion penetration depth }(\mathrm{mm}) \\ p_{d}^{\max } & \text { maximum corrosion penetration depth }(\mathrm{mm}) \\ t & \text { exposure period (years) } \\ T_{i} & \text { time-to-corrosion initiation (years) } \\ T_{e n v} & \text { temperature in the environment }(\mathrm{K}) \\ T_{i}^{1} & \text { time to first active corrosion }(\text { years }) \\ T_{i}^{\max } & \text { maximum value of time-to-corrosion initiation } \\ & \text { (years) }\end{array}$

$\begin{array}{ll}w / b & \text { water-to-binder ratio } \\ \theta_{a} & \text { angle between rebar center and } a \text { (degree) } \\ \theta_{b} & \text { angle between rebar center and } b \text { (degree) } \\ \theta_{\text {min }} & \text { minimum angle with rebar center (degrees) } \\ \theta_{\text {max }} & \text { maximum angle with rebar center (degrees) } \\ \kappa_{\alpha_{L}} & \text { binding isotherm constant (mL pore solution/g } \\ & \text { sample) } \\ \kappa_{\beta_{L}} & \text { binding isotherm constant (mL pore solution/mg } \\ & \text { Cl) } \\ \kappa_{\alpha_{F}} & \text { binding isotherm constant (mL pore solution/g } \\ & \text { sample) } \\ \kappa_{\beta_{F}} & \text { binding isotherm constant } \\ \eta_{1} & \text { regression coefficient } \\ \eta_{2} & \text { regression coefficient } \\ \lambda_{h} & \text { moisture diffusion coefficient } \\ \mu_{h} & \text { moisture diffusion coefficient } \\ v_{h} & \text { moisture diffusion coefficient } \\ v_{1} & \text { regression parameter } \\ v_{2} & \text { regression parameter } \\ \chi_{1} & \text { regression parameter } \\ \chi_{2} & \text { regression parameter } \\ \omega & \text { angular velocity (degree/year) } \\ \omega_{\text {max }} & \text { maximum angular velocity (degree/year) }\end{array}$

\section{References}

[1] Stewart M G and Suo Q H 2009 Extent of spatially variable corrosion damage as an indicator of strength and timedependent reliability of RC beams. Eng. Struct. 31: 198-207

[2] Bhargava K, Mori Y and Ghosh A K 2011 Time-dependent reliability of corrosion-affected RC beams - Part 1: Estimation of time-dependent strengths and associated variability. Nucl. Eng. Des. 241: 1371-1384

[3] Tuutti K 1982 Corrosion of steel in concrete, Swedish Cement and Concrete Research Institute

[4] Shafei B and Alipour A 2015 Application of large-scale nonGaussian stochastic fields for the study of corrosion-induced structural deterioration. Eng. Struct. 88: 262-276

[5] Marchand J and Samson E 2009 Predicting the service-life of concrete structures - Limitations of simplified models. $\mathrm{Ce}$ ment Concr. Compos.31: 515-521

[6] Saetta A V, Scotta R V and Vitaliani R V 1993 Analysis of chloride diffusion into partially saturated concrete. ACI Struct. J. 90: 441-451

[7] Martin-Perez B, Pantazopoulou S J and Thomas M D A 2001 Numerical solution of mass transport equations in concrete structures. Comput. Struct.79: 1251-1264

[8] Andrade C and Alonso C 2001 On-site measurements of corrosion rate of reinforcements. Constr. Build. Mater. 15: 141-145

[9] Angst U, Elsener B, Larsen C K and Vennesland O 2009 Critical chloride content in reinforced concrete - A review. Cem. Concr. Res.39: 1122-1138

[10] Muthulingam S and Rao B N 2014 Non-uniform time-tocorrosion initiation in steel reinforced concrete under chloride environment. Corros. Sci.82: 304-315 
[11] Muthulingam S and Rao B N 2015 Numerical assessment of non-uniform corrosion scenarios of rebar in concrete exposed to natural chloride environment. Sadhana 40: 1313-1341

[12] Oh B H and Jang B S 2003 Chloride diffusion analysis of concrete structures considering effects of reinforcements. ACI Mater. J.100: 143-149

[13] Pantazopoulou S J and Papoulia K D 2001 Modeling covercracking due to reinforcement corrosion in RC structures. ASCE J. Eng. Mech.127: 342-351

[14] Bhargava K, Ghosh A K, Mori Y and Ramanujam S 2003 Analytical model of corrosion-induced cracking of concrete considering the stiffness of reinforcement. Struct. Eng. Mech. 16: 749-769

[15] Liu Y P and Weyers R E 1998 Modeling the time-to-corrosion cracking in chloride contaminated reinforced concrete structures. ACI Mater. J. 95: 675-681

[16] Shafei B, Alipour A and Shinozuka M 2012 Prediction of corrosion initiation in reinforced concrete members subjected to environmental stressors: A finite-element framework. Cem. Concr. Res. 42: 365-376

[17] Otieno M, Beushausen H and Alexander M 2011 Prediction of corrosion rate in reinforced concrete structures - A critical review and preliminary results. Mater. Corros. 63: 777-790

[18] Li C Q, Melchers R E and Zheng J J 2006 Analytical model for corrosion-induced crack width in reinforced concrete structures. ACI Struct. J. 103: 479-487

[19] Val D V, Chemin L and Stewart M G 2009 Experimental and numerical investigation of corrosion-induced cover cracking in reinforced concrete structures. ASCE J. Struct. Eng. 135: 376-385

[20] Chen D and Mahadevan S 2008 Chloride-induced reinforcement corrosion and concrete cracking simulation. $\mathrm{Ce}$ ment Concr. Compos. 30: 227-238

[21] Zhao Y, Hu B, Yu J and Jin W 2011 Non-uniform distribution of rust layer around steel bar in concrete. Corros. Sci. 53: 4300-4308

[22] Zhao Y X, Karimi A R, Wong H S, Hu B Y, Buenfeld N R and Jin W L 2011 Comparison of uniform and non-uniform corrosion induced damage in reinforced concrete based on a Gaussian description of the corrosion layer. Corros. Sci. 53: 2803-2814
[23] Liu Y D and Li Y H 2004 Mechanistic model and numerical analysis for corrosion damage of reinforced concrete structure. Int. J. Fract. 126: 71-78

[24] Baroghel-Bouny V, Thiéry M and Wang X 2011 Modelling of isothermal coupled moisture-ion transport in cementitious materials. Cem. Concr. Res. 41: 828-841

[25] Muthulingam S and Rao B N 2015 Consistent models for estimating chloride ingress parameters in fly ash concrete. $J$. Buil. Eng. 3: 24-38

[26] Tang L P and Nilsson L O 1993 Chloride binding-capacity and binding isotherms of opc pastes and mortars. Cem. Concr. Res. 23: 247-253

[27] Xi Y P, Bazant Z P, Molina L and Jennings H M 1994 Moisture diffusion in cementitious materials - moisture capacity and diffusivity. Adv. Cem. Based Mater. 1: 258266

[28] Rodriguez J, Ortega L M, Casal J and Diez J M 1996 Corrosion of reinforcement and service life of concrete structures, Durability of Building Materials and Components 7, Stockholm, 117-126

[29] Vu K A T and Stewart M G 2000 Structural reliability of concrete bridges including improved chloride-induced corrosion models. Struct. Saf. 22: 313-333

[30] Japan Metereological Agency, http://www.data.jma.go.jp/ obd/stats/data/en/normal/normal.html. Accessed 15 December 2015

[31] Williamson S J and Clark L A 2000 Pressure required to cause cover cracking of concrete due to reinforcement corrosion. Mag. Concr. Res. 52: 455-467

[32] Xia N, Ren Q W, Liang R Y, Payer J and Patnaik A 2012 Nonuniform corrosion-induced stresses in steel-reinforced concrete. ASCE J. Eng. Mech. 138: 338-346

[33] Yuan Y S, Ji Y S and Mu Y J 2007 Propagation and model of distribution for corrosion of steel bars in concrete. China Civ. Eng. J. 40: 5-11

[34] Zandi H K, Lundgren K, Plos M and Coronelli D 2013 Three-dimensional modelling of structural effects of corroding steel reinforcement in concrete. Struct. Infrastruct. Eng. 9: 702-718

[35] Papakonstantinou K G and Shinozuka M 2013 Probabilistic model for steel corrosion in reinforced concrete structures of large dimensions considering crack effects. Eng. Struct. 57: 306-326 